OPEN ACCESS

Edited by: Takeshi Sakurai, University of Tsukuba, Japan

Reviewed by:

Radhika Basheer, Harvard Medical School,

United States

Hiromasa Funato,

Toho University, Japan

*Correspondence:

Christelle Anaclet

Christelle.Anaclet@umassmed.edu

Specialty section:

This article was submitted to Sleep and Circadian Rhythms, a section of the journal

Frontiers in Neuroscience

Received: 30 March 2019

Accepted: 08 July 2019

Published: 30 July 2019

Citation:

Erickson ETM, Ferrari LL

Gompf HS and Anaclet C (2019)

Differential Role of Pontomedullary Glutamatergic Neuronal Populations

in Sleep-Wake Control.

Front. Neurosci. 13:755.

doi: 10.3389/fnins.2019.00755

\section{Differential Role of Pontomedullary Glutamatergic Neuronal Populations in Sleep-Wake Control}

\author{
Evelyn T. M. Erickson, Loris L. Ferrari, Heinrich S. Gompf and Christelle Anaclet*
}

Department of Neurobiology, University of Massachusetts Medical School, Worcester, MA, United States

Parafacial zone (PZ) GABAergic neurons play a major role in slow-wave-sleep (SWS), also called non-rapid eye movement (NREM) sleep. The PZ also contains glutamatergic neurons expressing the vesicular transporter for glutamate, isoform 2 (Vglut2). We hypothesized that $\mathrm{PZ}$ Vglut2-expressing ( $\mathrm{PZ} \mathrm{Z}^{\text {Vglut2 }}$ ) neurons are also involved in sleep control, playing a synergistic role with PZ GABAergic neurons. To test this hypothesis, we specifically activated $P Z$ Vglut2 neurons using the excitatory chemogenetic receptor hM3Dq. Anatomical inspection of the injection sites revealed hM3Dq transfection in PZ, parabrachial nucleus (PB), sublaterodorsal nucleus (SLD) or various combinations of these three brain areas. Consistent with the known wake- and REM sleep-promoting role of $\mathrm{PB}$ and SLD, respectively, chemogenetic activation of $\mathrm{PB}$ Vglut2 or SLDVglut2 resulted in wake or REM sleep enhancement. Chemogenetic activation of $\mathrm{PZ}$ Vglut2 neurons did not affect sleep-wake phenotype during the mouse active period but increased wakefulness and REM sleep, similar to PBVglut2 and SLDVglut2 activation, during the rest period. To definitively confirm the role of $\mathrm{PZ} V$ glut2 neurons, we used a specific marker for $\mathrm{PZ} \mathrm{Z}^{\mathrm{V} g l u t 2}$ neurons, Phox2B. Chemogenetic activation of $\mathrm{PZ} \mathrm{Phox}^{\mathrm{B}}$ neurons did not affect sleep-wake phenotype, indicating that $P Z$ glutamatergic neurons are not sufficient to affect sleep-wake cycle. These results indicate that PZ glutamatergic neurons are not involved in sleep-wake control.

Keywords: neuronal circuitry, DREADDs, brainstem, parafacial zone, sleep-wake control, sublaterodorsal nucleus, parabrachial nucleus

\section{INTRODUCTION}

Over the past few years, the medullary parafacial zone (PZ) has been identified as a strong sleeppromoting brain area (Anaclet and Fuller, 2017). Both disruption of PZ GABAergic transmission (Anaclet et al., 2012) and chemogenetic inhibition of PZ GABAergic (PZ ${ }^{\mathrm{GABA}}$ ) neurons (Anaclet et al., 2014) result in insomnia. More importantly, chemogenetic activation of $\mathrm{PZ} \mathrm{GABA}^{\mathrm{GAA}}$ neurons strongly increases SWS amount and consolidation and enhances cortical EEG slow-wave activity (SWA), a marker of SWS depth (Anaclet et al., 2014). Finally, chemogenetic activation of PZ ${ }^{\mathrm{GABA}}$ neurons counteracts the wake-promoting action of psychostimulants (Anaclet et al., 2018). The $\mathrm{PZ}$ is generally located dorsal and lateral from the facial nerve but its exact boundaries are not precisely defined. A recent study has shown that, in mouse, the parvicellular reticular nucleus part alpha (PCRtA), ventral from PZ, does not contain sleep-active neurons (Sakai, 2017), indicating that the PZ sleep promoting neuronal population does not include the PCRtA. 
In rats, about $40 \%$ of $\mathrm{PZ}$ neurons are sleep-active (Alam et al., 2018) and cell body specific PZ lesions result in insomnia (Anaclet et al., 2012). More specifically, PZ $\mathrm{GABA}^{\mathrm{are}}$ involved in slow-wave-sleep (SWS) control. However, cFos expression, a marker of neuronal activity, showed that about half of sleep-active neurons are GABAergic (Anaclet et al., 2012), indicating that in the $\mathrm{PZ}$, non-GABAergic neurons are also involved in sleep control. Within the PZ, the only other known neuronal population is glutamatergic, expressing the vesicular glutamate transporter isoform 2 (Vglut2; in situ hybridization data are available in Allen Mouse Brain Atlas, Allen Institute for Brain Science ${ }^{1}$ ). We hypothesized that PZ glutamatergic neurons $\left(\mathrm{PZ}^{\mathrm{Vglut} 2}\right)$ are also involved in sleep control and act synergistically with sleep-active $\mathrm{PZ} \mathrm{GABA}^{\mathrm{n}}$ neurons to promote SWS. To start testing this hypothesis, we chemogenetically activated $\mathrm{PZ}$ Vglut2 neurons. Specific targeting of $\mathrm{PZ}$ was challenging and sleep phenotypes were difficult to interpret due to the possible transfection of the neighboring parabrachial (PB) and sublaterodorsal (SLD) nuclei that are involved in wakefulness and rapid eye movement (REM) sleep, respectively (Clement et al., 2011; Fuller et al., 2011). To get around these obstacles and specifically test the involvement of $\mathrm{PZ}$ glutamatergic neurons in sleep-wake control, we used Phox2B, a transcription factor expressed in PZ but not PB or SLD glutamatergic neurons. Data indicate that $\mathrm{PZ}$ glutamatergic neurons are not involved in sleepwake control. Additionally, we found that excitation of $\mathrm{PB}$ or SLD glutamatergic neurons promotes wakefulness or REM sleep, respectively, results that are complimentary to the reduction in wakefulness or REM sleep previously observed following lesion of PB or SLD, respectively (Clement et al., 2011; Fuller et al., 2011).

\section{MATERIALS AND METHODS}

\section{Animals}

In order to visualize Vglut2-, Phox2B- and Vgat-expressing neurons, Vglut2-IRES-cre [Jackson Laboratory \#016963 (Vong et al., 2011)], Phox2B-IRES-cre [Jackson Laboratory \#016223 (Rossi et al., 2011)] and Vgat-IRES-cre [Jackson Laboratory \#016962 (Vong et al., 2011)] mice were crossed with a credependent reporter mouse Flox-L10-GFP [Jackson Laboratory \#24750 (Liu et al., 2014)], producing Vglut2-GFP, Phox2B-GFP and Vgat-GFP mouse lines. Thirty two adult male Vglut2-GFP mice, seven adult male Phox2B-GFP and one adult male VgatGFP (8-12 weeks, 20-25 g) mice were used in this study. Mice were bred at our animal facility and underwent genotyping both before and after experiments. All procedures were approved by the Institutional Animal Care and Use Committee of Beth Israel Deaconess Medical Center and of University of Massachusetts Medical School.

\section{Surgery}

Naïve mice were anesthetized with ketamine/xylazine [100 and $10 \mathrm{mg} / \mathrm{kg}$, respectively, intraperitoneal (IP)] and then placed in a stereotaxic apparatus. To selectively express the hM3Dq

\footnotetext{
${ }^{1}$ http://mouse.brain-map.org/experiment/show/73818754
}

receptors in glutamatergic (Vglut2+) or Phox2B-expressing neurons of the PZ, we performed bilateral injections of an adenoassociated viral (AAV; serotype 10) vector expressing the hM3Dq receptor in a cre-dependent configuration [hSyn-DIO-hM3DqmCherry-AAV; (Anaclet et al., 2014)] into the PZ [coordinates from Bregma: Antero-posterior $=-5.6 \mathrm{~mm}$, Lateral $= \pm 1.0 \mathrm{~mm}$, Dorso-ventral $=-4.2 \mathrm{~mm}$, as per the mouse atlas of Paxinos and Watson (Paxinos and Franklin, 2001)] of Vglut2-IRES-cre (PZ $\left.{ }^{\text {Vglut2-hM3Dq }}\right)$ mice, Phox2B-IRES-cre (PZ $\left.{ }^{\text {Phox2B-hM3Dq }}\right)$ mice or non-cre expressing littermate control mice. Injections of the viral vector $(60 \mathrm{nl})$ into the $\mathrm{PZ}$ of these mice were performed using a compressed air delivery system as previously described (Anaclet et al., 2010). After injections, mice were implanted with four EEG screw electrodes (Pinnacle Technology Inc., Catalog \#8403) and two flexible electromyogram (EMG) wire electrodes (Plastics One, catalog \#E363/76/SPC), previously soldered to a 6-pin connector (Heilind Electronics, catalog \#853-43-006-10001000) and the assembly was secured with dental cement. The scalp wound was closed with surgical sutures and the mouse was kept in a warm environment until resuming normal activity as previously described (Anaclet et al., 2015).

\section{Sleep-Wake Monitoring}

Three weeks after surgery, the mice were housed individually in transparent barrels in an insulated sound-proofed recording chamber maintained at an ambient temperature of $22 \pm 1^{\circ} \mathrm{C}$ and on a $12 \mathrm{~h}$ light/dark cycle (lights-on at 7 A.M., Zeitgeber time: ZT0) with food and water available ad libitum. Mice were habituated to the recording cable for 5-7 days before starting polygraphic recording. Cortical EEG (ipsilateral frontoparietal leads) and EMG signals were amplified (A-M System 3500, United States) and digitalized with a resolution of $500 \mathrm{~Hz}$ using Vital Recorder (Kissei, Japan). Mice were recorded for a $24 \mathrm{~h}$ baseline period followed by IP injections of saline (control injection) or Clozapine-N-oxide (CNO, NIMH Chemical Synthesis and Drug Supply Program; $0.3 \mathrm{mg} / \mathrm{kg}$ in saline). Injections were performed at 10 A.M. (10:00, ZT3, light period, time of high sleep-drive) and 7 P.M. (19:00, ZT12, beginning of the dark period, time of high wake-drive), in a randomized cross-over design, with each injection separated by a 2-3 day washout period. In each experiment, recordings were simultaneously made from an equal number (batches of 2-4) of $\mathrm{PZ}^{\text {Vglut2-hM3Dq }}$ and $\mathrm{PZ}$ Vglut2-wt mice.

\section{Sleep Scoring and Analysis}

Using SleepSign for Animal (Kissei, Japan) assisted by spectral analysis using fast Fourier transform, polygraphic records were visually scored in $10 \mathrm{~s}$ epochs for wakefulness (W), SWS, and REM sleep. The percentage of time spent in wake, SWS and REM sleep were summarized for each group and each condition. The SWS to REM sleep latency is defined as the time between the onset of the first SWS episode, lasting $>20 \mathrm{~s}$, after injection and the onset of the first REM sleep episode, lasting $>10 \mathrm{~s}$.

Sleep-wake fragmentation was assessed by analyzing the distribution of each vigilance stage in different bout lengths. Vigilance stages were separated into eight bout lengths $(<30$, $40-70,80-150,160-310,320-630,640-1270,1280-2550$, and 
$>2550$ s) (Mochizuki et al., 2004; Kantor et al., 2013). For each vigilance stage, the number of episodes and the percentage of the vigilance stages occurring in each bout length were used to produce a time-weighted frequency histogram.

Recordings were scored again in $5 \mathrm{~s}$ epochs to allow for performance of an EEG power spectrum analysis. On the basis of visual and spectral analysis, epochs containing artifacts occurring during active wake (with large movements) or containing two vigilance states were visually identified and omitted from the spectral analysis. Recordings containing wake artifacts during more than $20 \%$ of the time were removed from the spectral analysis. EEG power spectra were computed for consecutive $5 \mathrm{~s}$ epochs within the frequency range of $0.5-120 \mathrm{~Hz}$ using a fast Fourier transform routine (FFT). The data were collapsed into $0.5 \mathrm{~Hz}$ bins. To determine the effect of injection on sleepwake power spectra, EEG power spectra were analyzed during the $3 \mathrm{~h}$ period of time post-injection, starting $10 \mathrm{~min}$ after injection as a previous study had shown that $\mathrm{CNO}$ injection significantly affected SWS amount during $3 \mathrm{~h}$ post-injection and SWS latency was no more than $10 \mathrm{~min}$ (Anaclet et al., 2014). The data were standardized by expressing each frequency bin as a percentage relative to the same bin under baseline conditions from the same mouse and from the same time of the day (same Zeitgeber time). To analyze the EEG frequency bands, power bins were summed in $\delta 0.5-5 \mathrm{~Hz}, \theta 5-9 \mathrm{~Hz}, \alpha$ 9-15 Hz, $\beta$ 15-30 Hz, low $\gamma$ 30-60 Hz and high $\gamma 60-120 \mathrm{~Hz}$, and expressed in percentage of baseline power band, from the same circadian time.

Statistical analysis was performed using Prism v6 (GraphPad Software, San Diego, CA, United States). Following confirmation that the data met the assumptions of the ANOVA model, twoway ANOVA followed by a post hoc Bonferroni test were used to compare the effects of the drug injection and time period on sleep-wake parameters, the effect of the drug injection and the distribution of vigilance episodes, or the effect of drug injection and power band on cortical EEG power density. Paired Student's $t$-test was used to compare the effects of the drug injection on SWS to REM sleep latency. Sample size and power calculations were performed post hoc at http://www. biomath.info, using means and standard deviations derived from our analysis. The present study was sufficiently powered to detect effect sizes.

\section{Immunostaining and RNAscope}

At the end of the behavioral experiments, mice were deeply anesthetized with ketamine/xylazine (200 and $20 \mathrm{mg} / \mathrm{kg}$, respectively) and perfused transcardially with $20 \mathrm{ml}$ of saline, followed by $100 \mathrm{ml}$ of neutral phosphate-buffered formalin (4\%; Thermo Fisher Scientific). Brains were removed from the skull and incubated in neutral phosphate-buffered formalin (4\%; Thermo Fisher Scientific) for $2 \mathrm{~h}$, followed by $20 \%$ sucrose until they sank.

For immunostaining, using a freezing microtome, brains were sectioned at $40 \mu \mathrm{m}$ into 3 series. One series was used to label mCherry to visualize neurons transfected by hSyn-DIO-hM3DqmCherry-AAV. Floating brain sections were incubated overnight with the primary antiserum (1:10,000; rabbit polyclonal antibody against mCherry was raised against DsRed, catalog \#632496,
Clontech). The next day, sections were incubated in goat antirabbit biotinylated secondary antiserum (1:1,000; catalog \# BA1000, Vector Laboratories), followed by incubation in $\mathrm{ABC}$ reagents (1:1000; Vector Laboratories) for $90 \mathrm{~min}$. Visualization reaction was in a $0.06 \%$ solution of 3,3-diaminobenzidine tetrahydrochloride (Sigma-Aldrich) in PBS plus $0.02 \% \mathrm{H}_{2} \mathrm{O}_{2}$ for 2-15 min. Finally, the sections were mounted on slides, dehydrated, cleared, and coverslipped. To map the extent of hSyn-DIO-hM3Dq-mCherry-AAV transfection, immunostained neurons were visualized with a brightfield microscope (Keyence BZ-X710, Japan) and mapped (Figures 1B, 3A, 4A, 7A).

For RNAscope, using a cryostat (Thermo Scientific, Cryostar NX70), brains were sectioned at $10 \mu \mathrm{m}$ and mounted onto Surgipath (Leica) adhesive microscope slides, 3 slices per slide. Slides were kept at $-80^{\circ} \mathrm{C}$ until shortly before in situ hybridization. Slides were first warmed to room temperature and then we performed the RNAscope hybridization using a RNAscope Multiplex Fluorescent Reagent Kit (Advanced Cell Diagnostics, Inc., Newark, CA, United States). Briefly, according to the manufacturer's instructions, target retrieval was performed at $99^{\circ} \mathrm{C}$ after which slices were dehydrated in $100 \%$ ethanol and air-dried. Next, sections were treated with protease inhibitor (Protease III, RNAscope) for $30 \mathrm{~min}$ at $40^{\circ} \mathrm{C}$. After rinsing in RNAscope wash buffer, we incubated the sections in the RNAscope probes for Vglut2 (Mm-Slc17a6, catalog \# 319171) and Phox2B (Mm-Phox2b-C2, catalog \# 407861-C2). Additional sections were incubated in the manufacturer-supplied 2-plex positive control (catalog \# 320761) and negative control (catalog \# 320751) probes. Following the first 3 signal amplification steps, the fourth amplification was performed using Amp 4 Alt C-FL, such that channel 1 (Vglut2) was fluorescently labeled with Alto 550 and channel 2 (Phox2B) was labeled with Alto 647. Fluorescent images were collected with a confocal microscope (Zeiss LSM 700; Figures 6D-P).

Figures 6A-C, Phox2B-GFP Native GFP fluorescence images were collected with a fluorescence microscope (Keyence BZ-X710, Japan).

\section{Whole-Cell in vitro Experiments}

For in vitro electrophysiological recordings, 10-13 days old Vglut2-ires-cre $(N=17)$ and Phox2B-ires-cre $(N=5)$ mice were injected bilaterally in the PZ, SLD or PB area with hSynDIO-hM3Dq-mCherry-AAV (100 nl/side). At about 3 weeks of age, $250 \mu \mathrm{m}$ thick coronal brain slices of the PZ, SLD or PB area were prepared.

Mice were deeply anesthetized (200 mg/Kg Ketamine, $20 \mathrm{mg} / \mathrm{Kg}$ Xylazine) and transcardially perfused with icecold $N$-methyl-D-glucamine based artificial cerebrospinal fluid (NMDG-ACSF) containing (in mM): NMDG 98, HEPES 20, Glucose 25, $\mathrm{NaHCO}_{3}$ 30, Na-ascorbate 5, Na-pyruvate 3, Thiourea 2, $\mathrm{MgSO}_{4}$ 10, $\mathrm{NaH}_{2} \mathrm{PO}_{4}$ 1.24, $\mathrm{KCl} 2.5, \mathrm{CaCl}_{2}$ 0.5; $\mathrm{pH}$ adjusted to $\approx 7.3$ with $\mathrm{HCl} 37 \%$. The brains were quickly extracted from the skull and sliced in carbogeneted (95\% O2 $5 \%$ CO2) ice-cold NMDG-ACSF using a vibrating microtome (7000-SMZ2, Campden Instruments). Slices containing the area of interest were immediately transferred to a chamber with carbogented NMDG-ACSF kept at $35^{\circ} \mathrm{C}$ for $8 \mathrm{~min}$, then moved to carbogeneted normal ACSF at room temperature containing 


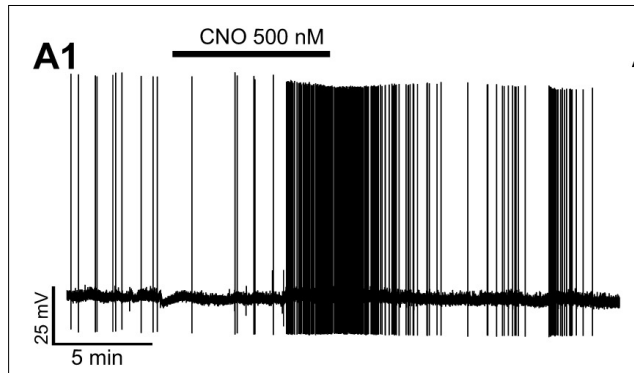

C1

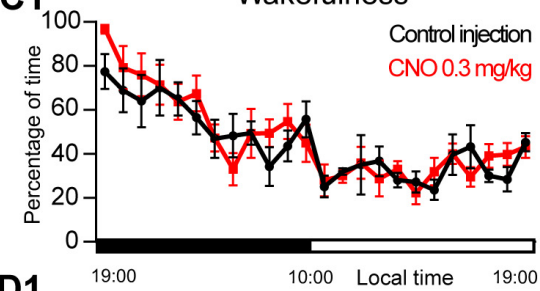

D1

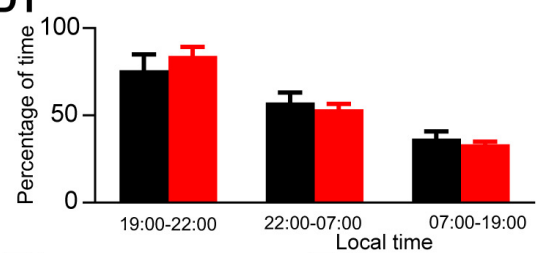

E1

E1'

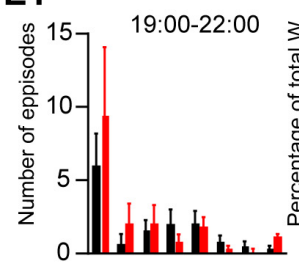

31007 19:00-22:00

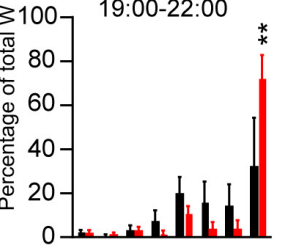



Length of $\mathrm{W}$ bout $(\mathrm{min})$

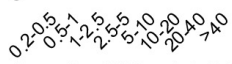

Length of $\mathrm{W}$ bout $(\mathrm{min})$

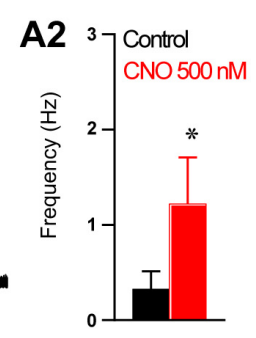

C2

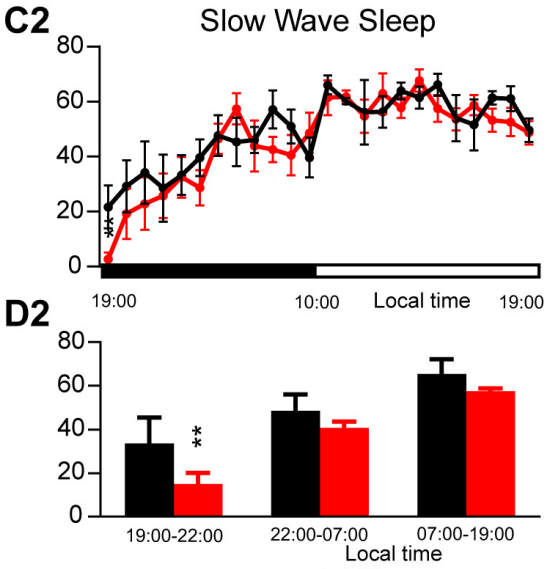

E2

E2'

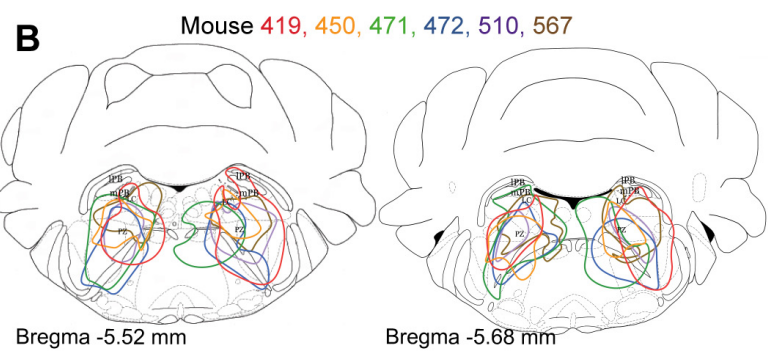

C3
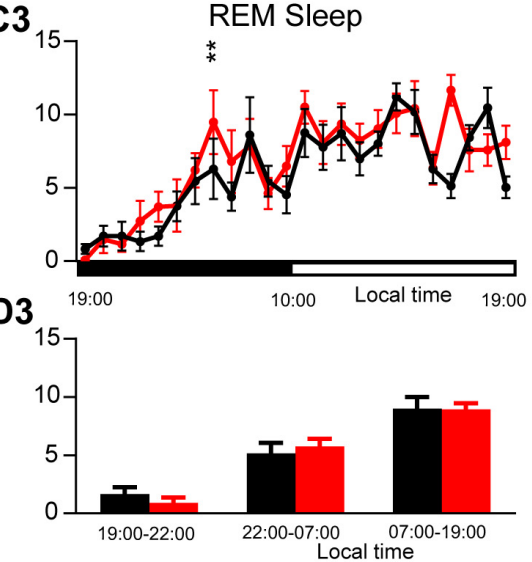

E3
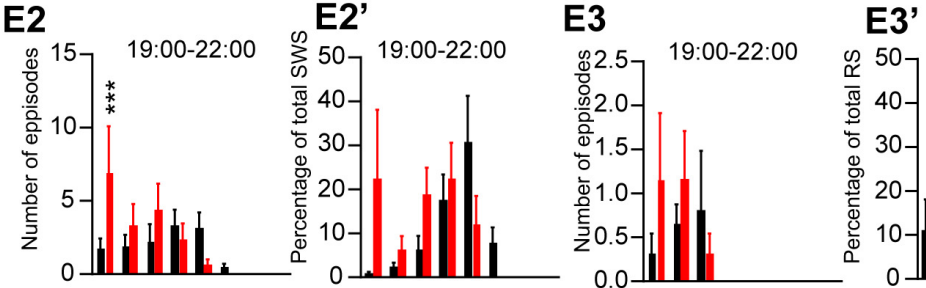

E3'
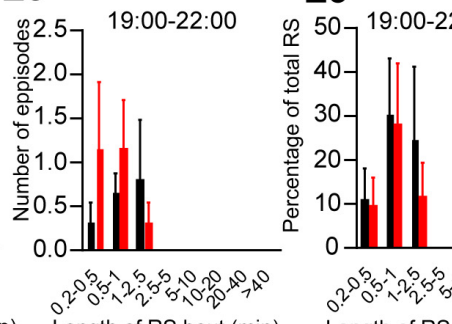

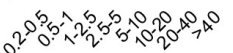

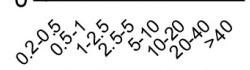

Length of SWS bout ( $\mathrm{min}$ ) Length of SWS bout ( $\mathrm{min}$ )

$\mathrm{F2}_{3}$

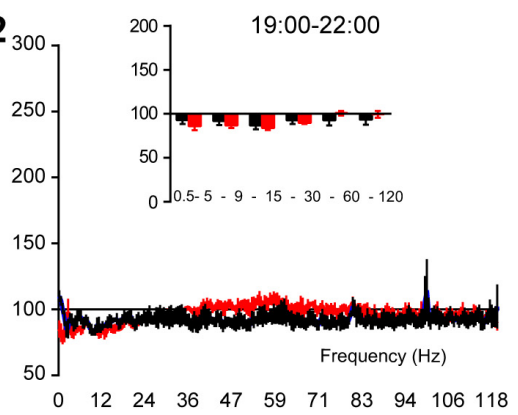

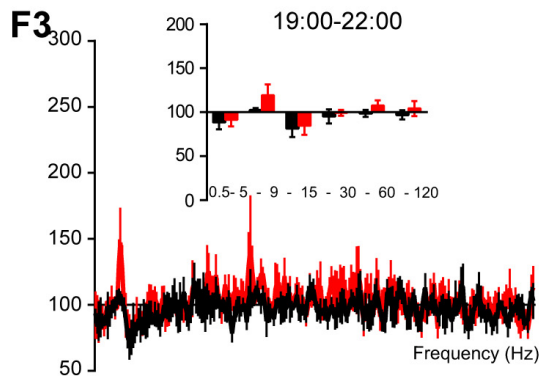

$\begin{array}{lllllllllll}0 & 12 & 24 & 36 & 47 & 59 & 71 & 83 & 94 & 106 & 118\end{array}$

FIGURE 1 | Activation of PZ glutamatergic neurons during the active period (19:00 or ZT12). (A) In vitro confirmation. (A1) PZVglut2-hM3Da whole-cell recording showing an increase in firing frequency in response to bath application of CNO $(0.5 \mu \mathrm{M})$. (A2) Average firing frequency $( \pm$ S.E.M.) during the last 2 min of the CNO $(0.5 \mu \mathrm{M})$ application as compared with the 2 min period preceding CNO application (control; $N=5$ PZVglut2-hM3Da neurons). * $p<0.05$ Paired Student's $t$-tests.

(B) Extent of transduced neurons (mCherry-positive somas) is shown for individual Vg/ut2-IRES-cre mice that received bilateral injections of hM3Dq-mCherry-AAV into the PZ (PZVglut2-hM3Dq). (C) Hourly amount of wakefulness (C1), SWS (C2) and REM sleep (C3) following CNO (0.3 mg/kg, N=6 mice) as compared with control injection. (D1-D3) Percentage of sleep-wake states ( \pm S.E.M.) during the $3 \mathrm{~h}$ post-injection period (19:00-22:00), the remainder $(9 \mathrm{~h})$ of the dark/active period (22:00-07:00) and the subsequent $12 \mathrm{~h}$ light period (07:00-19:00; $N=6$ mice). (E1-E3) Number of episodes ( \pm S.E.M.) of wakefulness (W), SWS or REM sleep (RS) in each bout length and (E1'-E3') time-weighted frequency histograms showing the proportion ( \pm S.E.M.) of W, SWS or RS amounts in each bout length as a percentage of the total amount of W, SWS or RS during the $3 \mathrm{~h}$ post-injection period (19:00-22:00; $N=6$ ). (F1-F3) Sleep-wake power spectrum changes over baseline during the $3 \mathrm{~h}(19: 00-22: 00)$ post CNO $(0.3 \mathrm{mg} / \mathrm{kg}, N=4$ mice) injection as compared with control injection; and the quantitative changes ( \pm S.E.M.) in power for the $\delta(0.4-5 \mathrm{~Hz}), \theta(5-9 \mathrm{~Hz}), \alpha(9-15 \mathrm{~Hz}), \beta(15-30 \mathrm{~Hz})$, low $\gamma(30-60 \mathrm{~Hz})$ and high $\gamma(60-120 \mathrm{~Hz})$ frequency bands ( \pm S. E.M.) following vehicle or CNO $\left(0.3 \mathrm{mg} / \mathrm{kg}, N=4\right.$ mice) administrations. (C-F) Control injection in Black, CNO injection in red; ${ }^{*} p<0.05,{ }^{* *} p<0.01,{ }^{* * *} p<0.001$, two-way ANOVA followed by a post hoc Bonferroni test. 
(in $\mathrm{mM}$ ): $\mathrm{NaCl} 126, \mathrm{NaHCO}_{3}$ 26, Glucose 10, Na-ascorbate 1, Thiourea 2, Na-Pyruvate 3, $\mathrm{NaH}_{2} \mathrm{PO}_{4}$ 1.24, $\mathrm{KCl} 2.5, \mathrm{CaCl}_{2} 2$, $\mathrm{MgCl}_{2}$ 1.3.

Recordings were guided using a combination of fluorescence and infrared differential interference contrast (IR-DIC) video microscopy using a fixed stage upright microscope (Axio Examiner.D1, Zeiss) equipped with a Nomarski immersion lens $(40 \times / 1.0)$ and an infrared-sensitive camera (Orca flash 4.0, Hamamatsu). Images were displayed in real time using Zen2 software (Carl Zeiss). Recordings were conducted in wholecell mode using an EPC-10 USB amplifier and Patchmaster software (Heka).

Recordings were performed in current clamp mode using a $\mathrm{K}$-gluconate based pipette solution containing (in $\mathrm{mM}$ ): $\mathrm{K}$ gluconate $120, \mathrm{KCl} 10, \mathrm{MgCl}_{2} 3$, HEPES 10, K-ATP, NaGTP 0.5. After at least $10 \mathrm{~min}$ of stable recording, ACSF containing CNO (500 $\mathrm{nM}$ ) was perfused into the chamber for 3-5 min before washout. Recordings were analyzed, using Patchmaster software, by comparing the last $2 \mathrm{~min}$ before the application of $\mathrm{CNO}$ to the last $2 \mathrm{~min}$ of the $\mathrm{CNO}$ application. Paired Student's $t$-tests were used to calculate statistical significance.

\section{RESULTS}

\section{PZVglut2 Neurons Are Not Sleep-Promoting}

To test whether activation of $\mathrm{PZ}^{\mathrm{V} \text { glut2 }}$ neurons affects sleepwake phenotype, Vglut2-IRES-Cre mice were injected into the $\mathrm{PZ}$ with a virus vector containing the excitatory hM3Dq receptor (AAV-mCherry-hM3Dq) to specifically express hM3Dq receptors in $\mathrm{PZ}$ glutamatergic neurons ( $\mathrm{PZ}$ Vglut2-hM3Dq mice). First, responses of $\mathrm{PZ}$ Vglut2-hM3Dq neurons to the hM3Dq ligand, clozapine-N-oxide (CNO), were tested using whole-cell in vitro recordings (Figure 1A1). Bath application of CNO (500 nM) significantly increased firing rates in $\mathrm{PZ}$ Vglut2-hM3Dq neurons (1.2 \pm 0.5 vs. $0.3 \pm 0.2 \mathrm{~Hz}$ in control condition, $p=0.042$; Figure 1A2), confirming that $\mathrm{CNO}$ activates $\mathrm{PZ}$ glutamatergic neurons. We then tested, in vivo, the sleep-wake phenotypes upon activation of $\mathrm{PZ}$ glutamatergic neurons. At the end of the behavioral studies, the injection sites were mapped using mCherry immunostaining. Of the sixteen Vglut2-IRES-Cre mice injected with AAV-mCherry-hM3Dq, six mice displayed more specific expression of mCherry bilaterally in the PZ (Figure 1B) and were used for the following sleep-wake analysis.

To test the effect of $\mathrm{PZ}$ Vglut2 neurons in sleep-wake control, mice were injected in a randomized cross-over design with saline or CNO $(0.3 \mathrm{mg} / \mathrm{kg})$ at the beginning of the dark/active period (19:00, ZT12) or during the light/rest period (10:00, ZT3). When injected at 19:00, CNO treatment did not significantly affect the hourly amount of wakefulness (two-way ANOVA, $F(23,115)=1.06, p=0.40 ;$ Figure 1C1), SWS (two-way ANOVA, $F(23,115)=1.02, p=0.45$; Figure 1C2), or REM sleep (two-way ANOVA, $F(23,115)=1.38, p=0.14$; Figure 1C3). Because in previous studies (Anaclet et al., 2014, 2015, 2018) the effect of CNO-mediated neuronal activation or inhibition on sleep-wake cycles was most pronounced during the $3 \mathrm{~h}$ post-injection period, we performed a more refined analysis of this period. Neither wakefulness nor REM sleep amount and consolidation were affected by $\mathrm{CNO}$ injection during the $3 \mathrm{~h}$ post $\mathrm{CNO}$ injection as compared with control injection (Figures 1D1,D3,E1,E1',E3,E3'). However, SWS amounts were significantly decreased during the $3 \mathrm{~h}$ post $\mathrm{CNO}$ injection period as compared with control injections (15.0 \pm 5.0 vs. $33.5 \pm 11.9 \%$ of SWS in control condition, $p<0.01$; Figure 1D2) but without change in bout length distribution (Figure 1E2'). This SWS decrease is associated with a significant increase in the number of very short SWS bouts $(7.0 \pm 3.1$ vs. $1.8 \pm 0.6$ bouts lasting between 10 and 30 s, $p=0.0006$; Figure 1E2). Wakefulness bout duration was also increased with a significant increase of the proportion of wakefulness from long bout lengths (>40 min long bouts: $72.9 \pm 10.1$ vs. $33.3 \pm 21.1 \%$ of total wakefulness after control injection, $p=0.003$; Figure 1E1'). These results indicate more labile switching between the two vigilance stages. Cortical EEG power spectral distribution was affected by the treatment in wakefulness (two-way ANOVA, $F(243,729)=1.48, p<0.0001$; Figure 1F1) and SWS (two-way ANOVA, $F(243,729)=3.88$, $p<0.0001$; Figure 1F2) but not in REM sleep (two-way ANOVA, $F(243,729)=0.82, p=0.97$; Figure 1F3). However, none of the frequency bands displayed any significant difference between $\mathrm{CNO}$ and control injection, in any vigilance stage (Figures 1F1F3). Altogether, activation of $\mathrm{PZ}$ glutamatergic neurons at a time when the wake-promoting systems are active, during the active phase, did not induce SWS and showed only minimal effects on sleep-wake phenotype, indicating that $\mathrm{PZ}$ Vglut2 neurons are not sleep-promoting.

In order to test if activation of $\mathrm{PZ}$ Vglut2 neurons affects sleepwake phenotypes differently when the sleep-promoting system is driving sleep, during the light period, CNO was injected at 10:00. CNO treatment significantly affected wakefulness (twoway ANOVA, $F(23,115)=3.14, p<0.0001$; Figure 2A1), SWS (two-way ANOVA, $F(23,115)=3.12, p<0.0001$; Figure 2A2) and REM sleep (two-way ANOVA, $F(23,115)=2.16, p=0.004$; Figure 2A3) hourly distribution. Wakefulness amount was significantly increased during the $4 \mathrm{~h}$ post CNO injection period (74.6 \pm 7.5 vs. $40.3 \pm 3.9 \%$ of time in control condition, $p<0.001$; Figure 2B1). This wakefulness increase was at the expense of SWS $(21.9 \pm 6.1$ vs. $53.5 \pm 4.2 \%$ of time in control condition, $p<0.001$; Figure 2B2). The increase in wakefulness was due to bout elongation, after $\mathrm{CNO}$ injection, as the mice were spending most of their wake time in bouts longer than $40 \min (44.5 \pm 11.2$ vs. $7.2 \pm 7.2 \%$ of total wakefulness after control injection, $p<0.001$; Figure 2C1'), while in control condition, they were spending most of their wake time in $20-40$ min long bouts $(15.5 \pm 8.2$ vs. $44.3 \pm 4.5 \%$ of total wakefulness in control condition, $p=0.01$; Figure 2C1'). The number of wakefulness episodes, however, remained unchanged (Figure 2C1). The decrease of SWS was due to fragmentation characterized by a significant increase in the number of very short SWS bouts $(13.0 \pm 4.0$ vs. $3.2 \pm 0.6$ episodes $30 \mathrm{~s}$ long or shorter in control condition, $p<0.0001$; Figure 2C2) and a significant decrease of long SWS bouts $(0.0 \pm 0.0$ vs. $27.8 \pm 6.1 \%$ of total SWS in bouts $10-20 \mathrm{~min}$ long in control condition, $p<0.0001$; Figure 2C2'). Interestingly, REM sleep amount displayed a trend to increase during the second part 



FIGURE 2 | Activation of PZ glutamatergic neurons during the inactive period (10:00 or ZT3). (A) Hourly amount of wakefulness (A1), SWS (A2) and REM sleep (A3) following CNO (0.3 mg/kg, $N=6$ mice) as compared with control injection. (B1-B3) Percentage of sleep-wake states ( \pm S.E.M.) during the $4 \mathrm{~h}$ post-injection period (10:00-14:00), the remainder ( $5 \mathrm{~h}$ ) of the light/sleep period (14:00-19:00), the subsequent $12 \mathrm{~h}$ light period and first $3 \mathrm{~h}$ of the light period of the next day (07:00-10:00, N = 6 mice). (C1-C3) Number of episodes ( \pm S.E.M.) of wakefulness (W), SWS or REM sleep (RS) in each bout length and (C1'-C3') time-weighted frequency histograms showing the proportion ( \pm S.E.M.) of W, SWS or RS amounts in each bout length as a percentage of the total amount of W, SWS or RS during the $4 \mathrm{~h}$ post-injection period (10:00-14:00; $N=6$ ). (D1-D3) Sleep-wake power spectrum changes over baseline during the $3 \mathrm{~h}(10: 00-13: 00)$ post CNO (0.3 mg/kg, $N=5$ mice) injection time period as compared with control injection; and the quantitative changes ( \pm S.E.M.) in power for the $\delta(0.4-5 \mathrm{~Hz}), \theta(5-9 \mathrm{~Hz}), \alpha(9-15 \mathrm{~Hz}), \beta$ (15-30 Hz), low $\gamma(30-60 \mathrm{~Hz})$ and high $\gamma(60-120 \mathrm{~Hz}$ ) frequency bands ( \pm S.E.M.) following vehicle or CNO $(0.3 \mathrm{mg} / \mathrm{kg}, N=5$ mice) administrations. Control injection in Black, CNO injection in red; ${ }^{*} p<0.05,{ }^{* *} p<0.01,{ }^{* * *} p<0.001,{ }^{* * * *} p<0.0001$, two-way ANOVA followed by a post hoc Bonferroni test.

of the light period, $4 \mathrm{~h}$ following CNO injection (14:00-19:00; $10.3 \pm 0.2$ vs. $8.5 \pm 0.7 \%$ of time after control injection, $p>0.05$; Figure 2B3). This was associated with a significant increase in the number of episodes (10-30 s long bouts: $7.0 \pm 1.3$ vs. $3.3 \pm 0.6$ bouts after control injection, $p<0.0001 ; 10-30 \mathrm{~s}$ long bouts: $12.5 \pm 0.6$ vs. $6.8 \pm 1.2$ bouts after control injection, $p<0.0001$; Figure 2C3). REM sleep bout length distribution, however, remained unchanged (Figure 2C3'). Cortical EEG power spectral distribution was not affected by the treatment in wakefulness (two-way ANOVA, $F(243,972)=0.76, p=0.996$; Figure 2D1). In contrast, both SWS (two-way ANOVA, $F(243,972)=2.79$, $p<0.0001$; Figure 2D2) and REM sleep (two-way ANOVA,
$F(243,972)=1.43, p=0.0001$; Figure 2D3) cortical EEG power spectral distribution was affected by the treatment. Interestingly, during REM sleep, the theta band was significantly increased $(128.1 \pm 6.3$ vs. $106.9 \pm 3.2 \%$ of baseline theta power in control condition, $p<0.001$; Figure 2D3).

\section{Activation of SLDVglut2 Neurons During the Inactive Period Enhances REM Sleep}

The excitatory receptor, hM3Dq, was mostly expressed in the SLD in six Vglut2-hM3Dq mice (SLD Vglut2-hM3Dq; Figure 3A). Whole-cell recording confirmed the expression of functional 

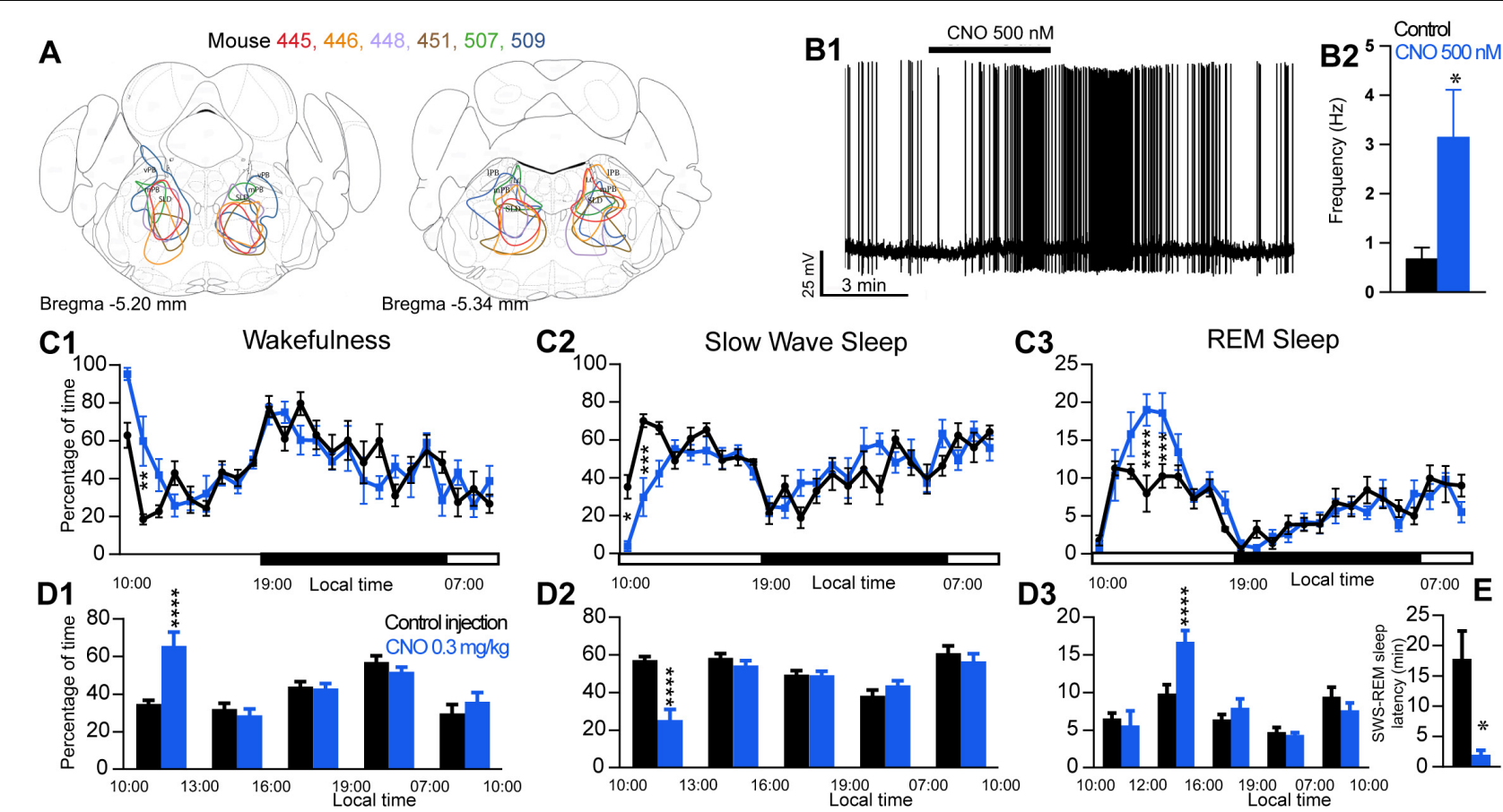

F1



F1'

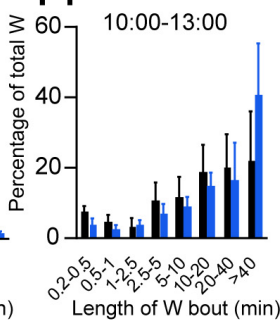

G1

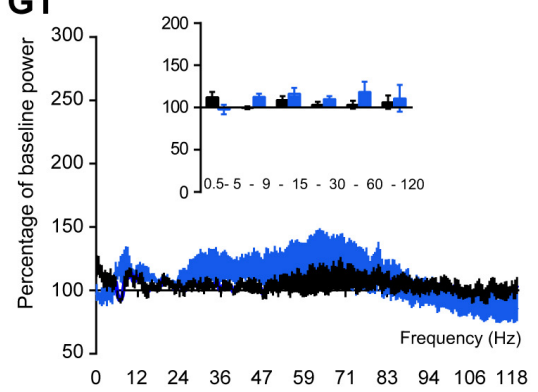

F2

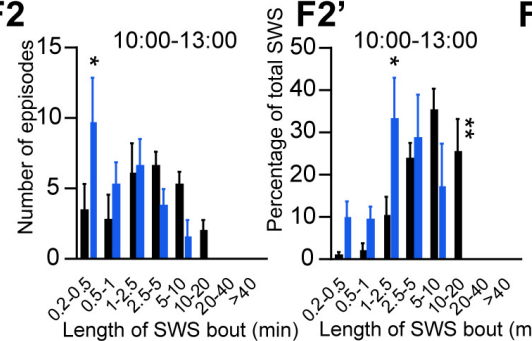

G2

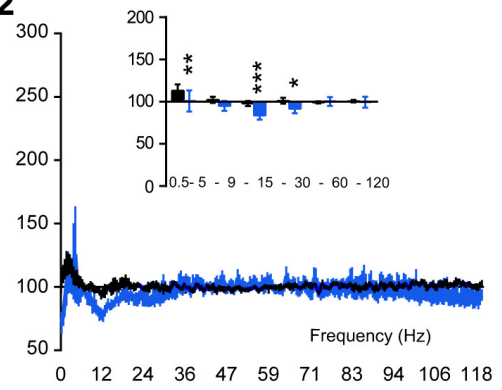

C3

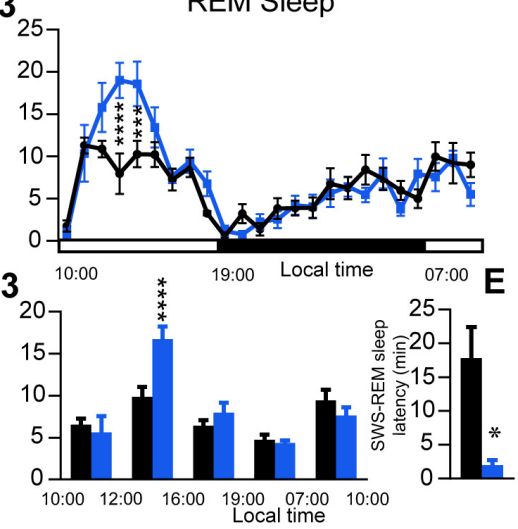

F3



F3'

G3

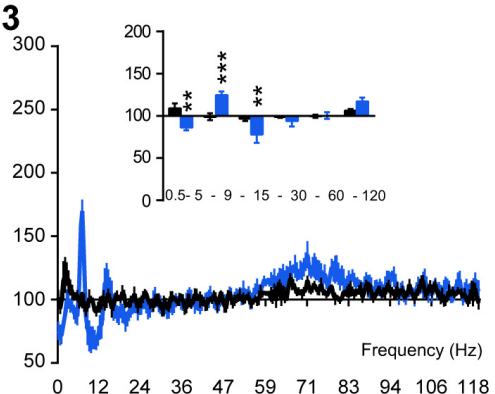

FIGURE 3 | Activation of SLD glutamatergic neurons during the inactive period (10:00 or ZT3). (A) Extent of transduced neurons (mCherry-positive somas) is shown for individual Vglut2-IRES-cre mice that received bilateral injections of hM3Dq-mCherry-AAV into the SLD (SLDVglut2-hM3Dq). (B1) SLDVglut2-hM3Dq whole-cell recording showing an increase in firing frequency in response to bath application of CNO $(0.5 \mu M)$. (B2) Average firing frequency ( \pm S.E.M.) during the last 2 min of the CNO $(0.5 \mu \mathrm{M})$ application as compared with the 2 min period preceding CNO application (control; $N=6$ PB ${ }^{r m V g / u t 2-h M 3 D q}$ neurons). * $p<0.05$ Paired Student's t-tests. (C) Hourly amount of wakefulness (C1), SWS (C2) and REM sleep (C3) following CNO (0.3 mg/kg, $N=6$ mice) as compared with control injection. (D1,D2) Percentage of wakefulness and SWS ( \pm S.E.M.), respectively, during the $3 \mathrm{~h}$ post-injection period (10:00-13:00), the following $3 \mathrm{~h}$ (13:00-16:00), the remainder (3 h) of the light/sleep period (16:00-19:00), the subsequent $12 \mathrm{~h}$ dark period (19:00-07:00) and first $3 \mathrm{~h}$ of the light period of the next day (07:00-10:00, $\mathrm{N}=6 \mathrm{mice})$. (D3) Percentage of REM sleep ( \pm S.E.M.) during the $2 \mathrm{~h}$ post-injection period (10:00-12:00), the following $4 \mathrm{~h}$ (12:00-16:00), the remainder (3 h) of the light/sleep period (16:00-19:00), the subsequent $12 \mathrm{~h}$ dark period (19:00-07:00) and first $3 \mathrm{~h}$ of the light period of the next day (07:00-10:00, $\mathrm{N}=6 \mathrm{mice}$ ). (E) SWS to REM sleep latency defined as the time (min) between the onset of the first SWS episode (>20 s) and the onset of the first REM sleep episode (>10 s). (F1-F3) Number of episodes ( \pm S.E.M.) of wakefulness (W), SWS or REM sleep (RS) in each bout length and (F1'-F3') time-weighted frequency histograms showing the proportion ( \pm S.E.M.) of W, SWS or RS amounts in each bout length as a percentage of the total amount of W, SWS during the $3 \mathrm{~h}$ post-injection period (10:00-13:00) or RS during the 12:00-16:00 period ( $N=6)$. (G1-G3) Sleep-wake power spectrum changes over baseline during the $3 \mathrm{~h}(10: 00-13: 00)$ post $\mathrm{CNO}(0.3 \mathrm{mg} / \mathrm{kg}, \mathrm{N}=6$ mice) injection as compared with control injection; and the quantitative changes ( \pm S.E.M.) in power for the $\delta(0.4-5 \mathrm{~Hz}), \theta(5-9 \mathrm{~Hz}), \alpha(9-15 \mathrm{~Hz}), \beta(15-30 \mathrm{~Hz})$, low $\gamma$ (30-60 Hz) and high $\gamma(60-120 \mathrm{~Hz})$ frequency bands ( \pm S.E.M.) following vehicle or CNO $(0.3 \mathrm{mg} / \mathrm{kg}, \mathrm{N}=6 \mathrm{mice})$ administrations. (C-G) Control injection in Black, CNO injection in blue; ${ }^{*} p<0.05,{ }^{* *} p<0.01,{ }^{* * *} p<0.001,{ }^{* * *} p<0.0001$, two-way ANOVA followed by a post hoc Bonferroni test. 
hM3Dq receptors (Figure 3B1). CNO (500 nM) application significantly increased the firing rate of SLD neurons $(3.15 \pm 0.96$ vs. $0.68 \pm 0.23 \mathrm{~Hz}$ in control condition, $p=0.032$, Figure $3 \mathrm{~B} 2$ ). Sleep-wake analysis during the inactive phase (10:00) revealed that $\mathrm{CNO}(0.3 \mathrm{mg} / \mathrm{kg}, n=6,10: 00)$ injection significantly affected wakefulness (two-way ANOVA, $F(23,115)=2.38, p=0.0014$; Figure 3C1), SWS (two-way ANOVA, $F(23,115)=2.82$, $p=0.0001$; Figure 3C2) and REM sleep (two-way ANOVA, $F(23,115)=3.30, p<0.0001$; Figure 3C3) in SLD Vglut2-hM3Dq mice, as compared with control injection. Wakefulness was significantly increased during the $3 \mathrm{~h}$ post $\mathrm{CNO}$ injection period $(65.0 \pm 8.8$ vs. $34.8 \pm 2.1 \%$ of time after control injection, $p<0.0001$; Figure 3D1). At the same time, SWS amount was significantly decreased $(25.9 \pm 7.0$ vs. $57.3 \pm 1.8 \%$ of time after control injection, $p<0.0001$; Figure 3D2). REM sleep amount remained unchanged during the $2 \mathrm{~h}$ post CNO injection period $(6.2 \pm 2.2$ vs. $6.5 \pm 0.7 \%$ of time after control injection, $p>0.05$; Figure 3D3). However, REM sleep amount was significantly increased during the $2-6 \mathrm{~h}$ post-injection period (15.5 \pm 1.1 vs. $9.8 \pm 1.2 \%$ of time after control injection, $p<0.0001$; Figure 3D3). Interestingly, the SWS to REM sleep latency was significantly decreased after CNO injection $(2.0 \pm 0.7$ vs. $17.8 \pm 4.6 \mathrm{~min}$ between the beginning of the first SWS episode and the beginning of the first REM sleep episode in control condition, $p=0.018$; Figure $3 \mathrm{E}$ ). The observed wakefulness increases during the $3 \mathrm{~h}$ post $\mathrm{CNO}$ injection resulted from a non-significant increase in both the number of long bouts (>40 min; Figure 3F1) and in the proportion of wakefulness from long bouts ( $>40 \mathrm{~min}$; Figure 3F1'). SWS decrease was due to a significant decrease of the proportion of SWS from long SWS bouts $(0.0 \pm 0.0$ vs. $26.0 \pm 7.2 \%$ of total SWS from $10-$ 20 min long bouts in control condition, $p=0.0038$, Figure 3F2'), associated with a significant increase in the proportion of SWS from short SWS bouts $(33.7 \pm 9.2$ vs. $10.8 \pm 3.9 \%$ of total SWS from 1-2.5 min long bouts in control condition, $p=0.014$, Figure 3F2'). At the same time, the number of very short SWS bouts (10-30 s long) were significantly increased $(9.8 \pm 3.0$ vs. $3.5 \pm 1.8$ bouts in control condition, $p=0.015$, Figure 3F2). The REM sleep increase $2-6 \mathrm{~h}$ post $\mathrm{CNO}$ injection was due to a significant increase in the number of medium-duration bouts $(6.6 \pm 1.6$ vs. $3.6 \pm 1.10 .5-1 \mathrm{~min}$ long bouts in control condition, $p<0.0001$; and $12.4 \pm 3.0$ vs. $6.8 \pm 1.21-2.5 \mathrm{~min}$ long bouts in control condition, $p<0.0001$, Figure 3F3) while REM sleep bout length is moderately affected (Figure 3F3').

Cortical EEG power distribution was affected by $\mathrm{CNO}$ administration during wakefulness (two-way ANOVA, $F(243,972)=3.16, p<0.0001$; Figure 3G1), SWS (two-way ANOVA, $F(243,972)=2.27, p<0.0001$; Figure 3G2) and REM sleep (two-way ANOVA, $F(243,972)=4.89, p<0.0001$; Figure 3G3). During SWS, delta ( $101.1 \pm 12.5$ vs. $113.3 \pm 7.4 \%$ of baseline power in control condition, $p<0.01)$, sigma $(83.8 \pm 4.7$ vs. $98.0 \pm 3.2 \%$ of baseline power in control condition, $p<0.001)$ and beta $(91.9 \pm 5.3$ vs. $98.0 \pm 3.2 \%$ of baseline power in control condition, $p<0.05$ ) power bands were decreased (Figure 3G2). During REM sleep, both delta (86.5 \pm 3.2 vs. $109.0 \pm 5.9 \%$ of baseline power in control condition, $p<0.01$ ) and sigma $(78.1 \pm 10.1$ vs. $96.8 \pm 3.0 \%$ of baseline power in control condition, $p<0.01)$ frequency bands were significantly decreased whereas theta $(125.0 \pm 3.9$ vs. $99.1 \pm 3.9 \%$ of baseline power in control condition, $p<0.001$ ) was significantly increased (Figure 3G3). Similar to PZ Vglut2-hM3Dq mice, SLD Vglut2-hM3Dq did not show any sleep-wake phenotypes when $\mathrm{CNO}$ was injected at the beginning of the dark/active period (data not shown), indicating a time of the day difference.

\section{Activation of PB ${ }^{\text {Vglut2 }}$ Neurons Induces Wakefulness}

The excitatory receptor, $\mathrm{hM} 3 \mathrm{Dq}$, was mostly expressed in the $\mathrm{PB}$ in five Vglut2-hM3Dq mice ( $\mathrm{PB}$ Vglut2-hM3Dq; Figure 4A). Slice electrophysiology showed that firing rates of $\mathrm{PB}^{\text {Vglut2-hM3Dq }}$ neurons were significantly increased $(1.48 \pm 0.40$ vs. $0.32 \pm 0.04 \mathrm{~Hz}$ in control condition, $p=0.042)$ by bath application of $\mathrm{CNO}(500 \mathrm{nM}$; Figures 4B1,B2). Injection of $\mathrm{CNO}(0.3 \mathrm{mg} / \mathrm{kg}, 10: 00)$ in $\mathrm{PB}^{\text {Vglut2-hM3Dq }}$ mice significantly affected wakefulness (two-way ANOVA, $F(23,92)=6.12, p<0.0001$; Figure 4C1), SWS (two-way ANOVA, $F(23,92)=6.24, p<0.0001$; Figure 4C2) and REM sleep (two-way ANOVA, $F(23,92)=3.44, p<0.0001$; Figure 4C3). Wakefulness amount was significantly increased during the remaining $9 \mathrm{~h}$ of the light period post-injection $(79.3 \pm 9.5$ vs. $32.4 \pm 1.5 \%$ of time, $p<0.001$; Figure $4 \mathrm{D1})$ At the same time, both SWS (17.8 \pm 7.8 vs. $59.1 \pm 1.4 \%$ of time, $p<0.001$; Figures 4C2-D3) and REM sleep (2.9 \pm 1.7 vs. $8.5 \pm 0.4 \%$ of time, $p<0.01$; Figures 4C3-D3) amount were significantly decreased. No sleep rebound followed the long-lasting wakefulness increase $(47.5 \pm 1.1$ vs. $47.7 \pm 2.7 \%$ of time spent in SWS during the following dark period, 19:00-07:00, $p>0.05$; Figures 4C2,D2). Wakefulness enhancement was due to a significant increase in bout length $(76.7 \pm 7.3$ vs. $0.0 \pm 0.05$ of wakefulness from $>40$ min long bouts, $p<0.0001$, Figure 4E1'), associated with a significant decrease in the number of short episodes (Figure 4E1). Both SWS bout number (5.6 \pm 2.5 vs. $20.8 \pm 2.15-10 \mathrm{~min}$ long bouts, $p=0.0002$; Figure 4E2) and bout duration $(3.4 \pm 2.4$ vs. $23.9 \pm 6.6 \%$ of SWS in $10-20 \mathrm{~min}$ long bouts, $p=0.025$; Figure 4E2') were significantly decreased. Similarly, both REM sleep bout number (Figure 4E3) and bout duration (Figure 4E3') were significantly decreased during the $5 \mathrm{~h}$ period following injection. Cortical EEG power distribution was affected by CNO injection during wakefulness (two-way ANOVA, $F(543,972)=1.66, p<0.0001$; Figure 4F1). $\mathrm{PB}^{\text {Vglut2 }}$ induced wakefulness was characterized by a significant decrease in cortical EEG delta power $(49.9 \pm 5.2$ vs. $102.1 \pm 7.4 \%$ of baseline power in control condition, $p<0.01$; Figure 4F2). Similar results were obtained when $\mathrm{CNO}$ was injected at the beginning of the active period (19:00; not shown).

\section{CNO Does Not Affect Sleep-Wake Cycle in Control Mice}

To control for non-specific actions of CNO, non-cre expressing littermate mice were used. No hM3Dq receptor transfection was seen in these control mice. Treatment did not affect the hourly distribution of wakefulness (two-way ANOVA, $F(23,92)=1.53$, $p=0.082$; Figure 5A1), SWS (two-way ANOVA, $F(23,92)=1.56$, 


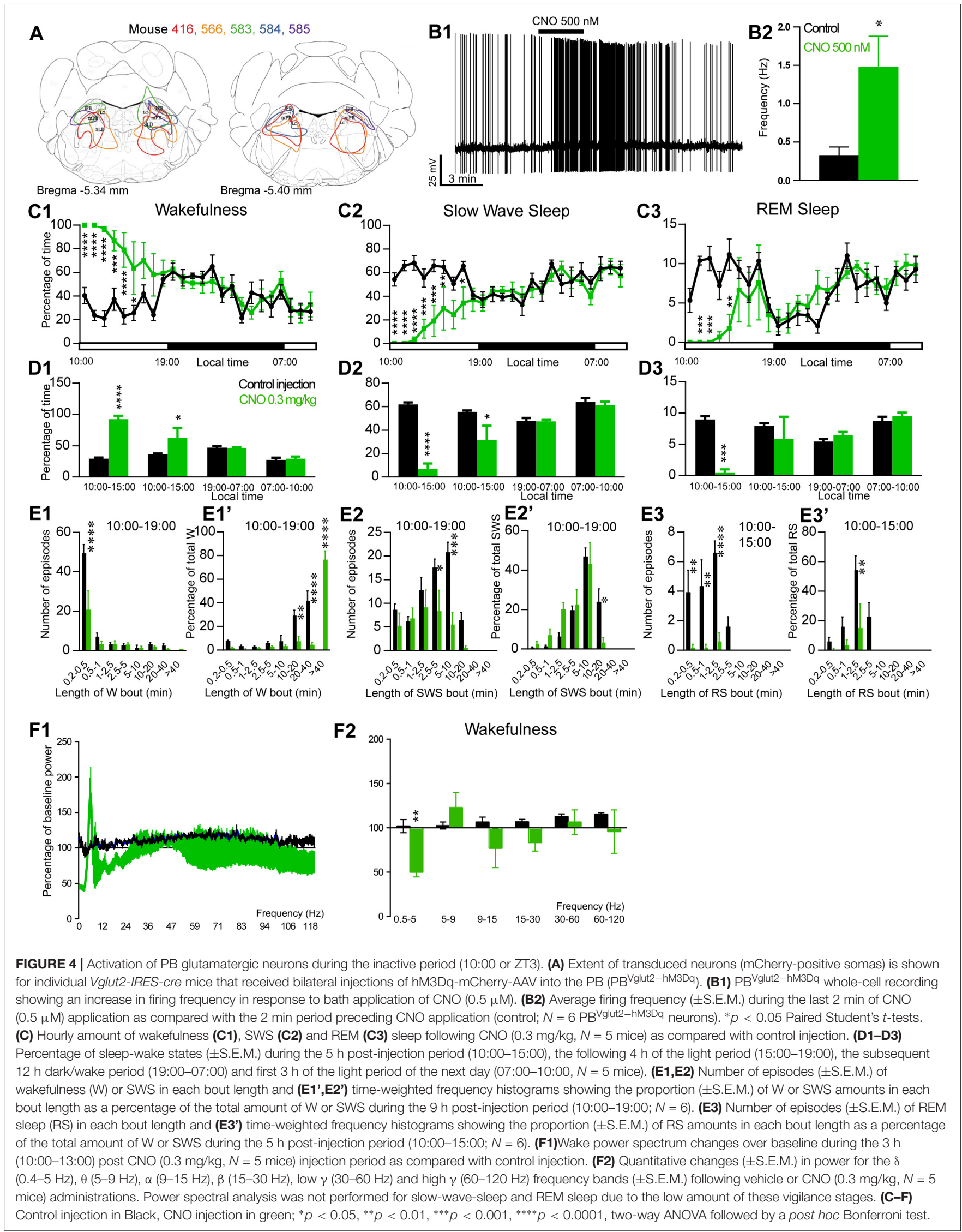





FIGURE 5 | CNO injection (10:00 or ZT3) in control mice. (A) Hourly amount of wakefulness (A1), SWS (A2) and REM (A3) sleep following CNO (0.3 mg/kg, $N=5$ mice) as compared with control injection. (B1-B3) Number of episodes ( \pm S.E.M.) of wakefulness (W), SWS or REM sleep (RS) in each bout length and (B1'-B3') time-weighted frequency histograms showing the proportion ( \pm S.E.M.) of W, SWS or RS amounts in each bout length as a percentage of the total amount of W, SWS or RS during the $3 \mathrm{~h}$ post-injection period (10:00-13:00; $N=5$ ). (C1-C3) Sleep-wake power spectrum changes over baseline during the $3 \mathrm{~h}(10: 00-13: 00)$ post CNO $(0.3 \mathrm{mg} / \mathrm{kg}, N=5$ mice) injection as compared with control injection; and the quantitative changes ( \pm S.E.M.) in power for the $\delta(0.4-5 \mathrm{~Hz}), \theta(5-9 \mathrm{~Hz}), \alpha$ (9-15 Hz), $\beta(15-30 \mathrm{~Hz})$, low $\gamma(30-60 \mathrm{~Hz})$ and high $\gamma(60-120 \mathrm{~Hz})$ frequency bands ( \pm S.E.M.) following vehicle or CNO $(0.3 \mathrm{mg} / \mathrm{kg}, N=5 \mathrm{mice})$ administrations. Control injection in Black, CNO injection in magenta; no significant change, two-way ANOVA followed by a post hoc Bonferroni test.

$p=0.071$; Figure 5A2) or REM sleep (two-way ANOVA, $F(23,92)=1.06, p=0.4$; Figure 5A3). Moreover, CNO treatment did not affect the number of episodes or the episode length distribution as compared with control injection (Figures 5B1B3') in any vigilance state. Finally, the cortical EEG power distribution during wakefulness, SWS and REM sleep was similar after CNO injection, as compared with both control injection and baseline recording (Figures 5C1-C3). These results confirm that the sleep-wake effects seen in $\mathrm{PZ}$ Vglut2-hM3Dq, $\mathrm{PB}^{\text {Vglut2-hM3Dq }}$ and SLD ${ }^{\text {Vglut2-hM3Dq }}$ mice is due to the specific activation of glutamatergic neurons.

\section{Phox2B Is a Specific Marker for PZ Glutamatergic Neurons}

Because chemogenetic activation of $\mathrm{PZ}$ Vglut2 neurons resulted in phenotypes resembling chemogenetic activation of $\mathrm{PB}$ Vglut2 and SLD ${ }^{\text {Vglut2 }}$ neurons, i.e., wakefulness and REM sleep increase, respectively, we hypothesized that in the $\mathrm{PZ}$ Vglut2-hM3Dq mouse group some $\mathrm{PB}^{\text {Vglut2 }}$ and $\mathrm{SLD}^{\text {Vglut2 }}$ neurons were transfected and therefore responsible for the phenotypes. To specifically target PZ glutamatergic neurons we took advantage of a specific marker for $\mathrm{PZ}$ glutamatergic neurons, Phox2B. In the adult rat medullary and pontine regions in proximity to the $\mathrm{PZ}$, Phox2B expression is restricted to the $\mathrm{PZ}$, with a notable lack of expression in either the PB or the SLD (Kang et al., 2007). Moreover, Phox2B is co-localized with Vglut2 but not with Vgat or GAD67 [Figures 6D-G; (Stornetta et al., 2006)], suggesting that $\mathrm{Phox} 2 \mathrm{~B}$ is a specific marker for $\mathrm{PZ}$ glutamatergic neurons. We first confirmed the presence of Phox $2 \mathrm{~B}$ expression in $\mathrm{PZ}$ (Figure 6A) of mouse using Phox2B-GFP mice. No GFP positive neurons were seen in either the $P B$ or the SLD (Figures 6B,C), indicating that Phox2B is specific for PZ glutamatergic neurons. Neurons of the locus coeruleus were GFP positive (LC; Figures 6A,B), which is consistent with previous studies showing that Phox $2 \mathrm{~B}$ is necessary for the differentiation of central noradrenergic and adrenergic neurons (Pattyn et al., 2000; Huber et al., 2005). We then assessed the extent of co-localization between Vglut2 and Phox2B in PZ. In each of the slices containing the PZ ( $n=12$ from 4 mice), Vglut2 co-localized exclusively with Phox $2 \mathrm{~B}$ and Phox $2 \mathrm{~B}$ was found primarily lateral to the facial nerve, in the entire $\mathrm{PZ}$ area (Figures $\mathbf{6 H}-\mathbf{K}$ ). Higher magnification photomicrographs show the cellular details of Vglut2/Phox2B co-localization 

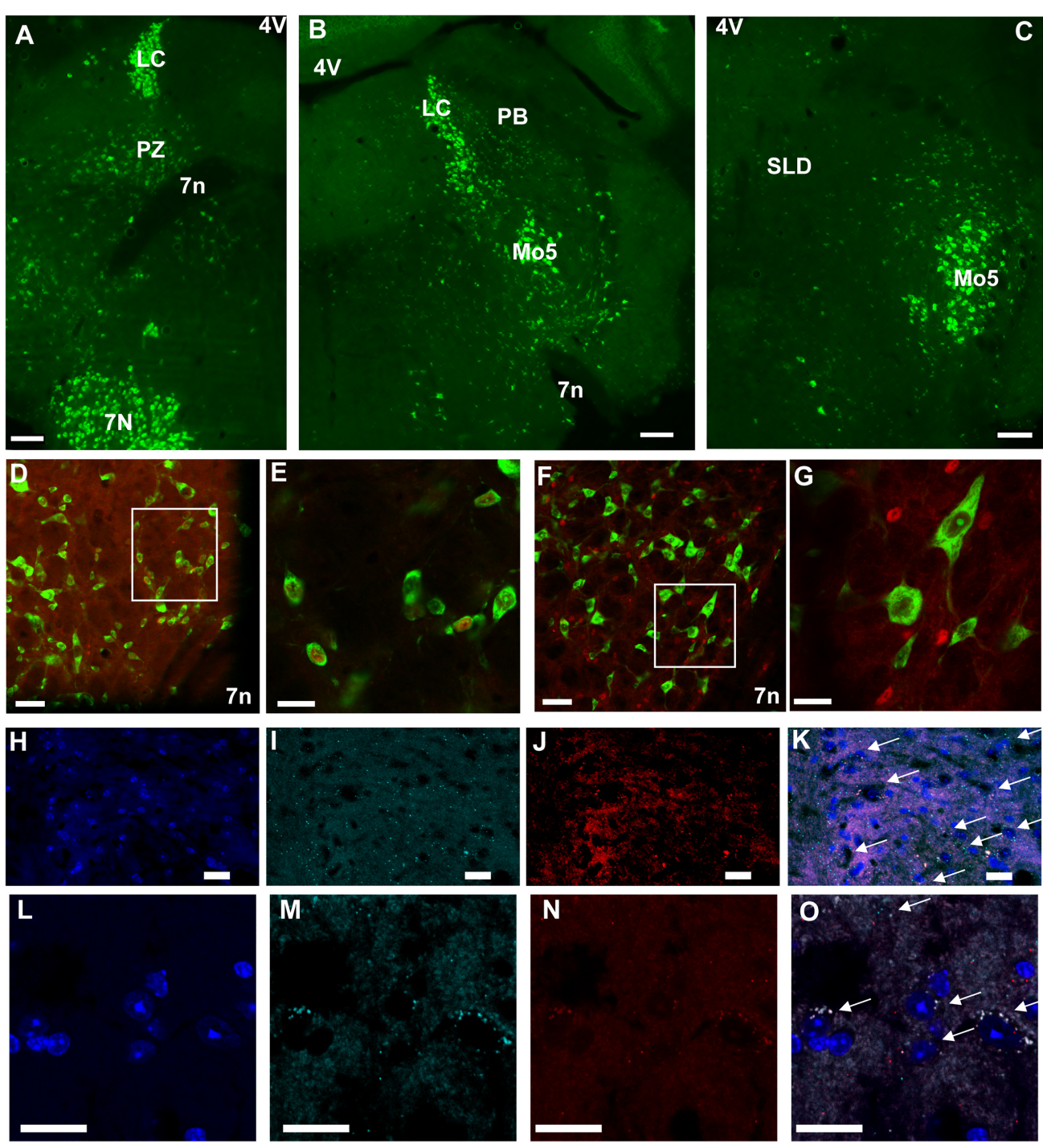

FIGURE 6 | Phox2B is expressed in PZ and is co-localized with Vglut2. (A-C) Images from a Phox2B-GFP mouse brain showing Phox2B-expressing neurons in PZ (A) but not in PB (B) or SLD (C). Scale bar: $200 \mu \mathrm{m}$. (D) Confocal images from PZ showing native GFP from a Vglut2-GFP mouse immunolabeled for Phox2B in red. Scale bar: $50 \mu \mathrm{m}$. (E) Higher magnification of the box in (D). Scale bar: $20 \mu \mathrm{m}$. (F) Confocal images from PZ showing native GFP from a Vgat-GFP mouse immunolabeled for Phox2B in red. Scale bar: $50 \mu \mathrm{m}$. (G) higher magnification of the box in (F). Scale bar: $20 \mu \mathrm{m}$. (H-O) Confocal images of the PZ showing DAPI staining of nuclei $\mathbf{( H , L )}$, and mRNA of Vglut2 $\mathbf{( I , M )}$ and Phox2B $(\mathbf{J}, \mathbf{N})$ from two mice. The merged images show complete overlap of both mRNA expression (arrows in K,O). Scale bar: $20 \mu \mathrm{m}$. Abbreviations: $4 \mathrm{~V}$, fourth ventricle; $7 \mathrm{n}$, seventh facial nerve; LC, locus coeruleus; Mo5, motor trigeminal nucleus; PB, parabrachial nucleus; PZ, parafacial zone; SLD, sublaterodorsal nucleus.

Figures 6L-O). Therefore, Phox2B is a specific marker for $\mathrm{PZ}$ glutamatergic neurons and Phox2B-IRES-cre mice can be used to specifically activate $\mathrm{PZ}$ glutamatergic neurons and study their role in sleep-wake control.

\section{Activation of $\mathrm{PZ}{ }^{\text {Phox2B }}$ Neurons Does Not Affect Sleep-Wake Cycle}

To assess the involvement of $\mathrm{PZ}$ glutamatergic neurons, five Phox2B-IRES-Cre mice were injected into the PZ with AAVhM3Dq-mCherry (Figure 7A). Three of the five cases also showed partial expression in the LC. Whole-cell in vitro recording (Figure 7B1) confirmed that bath application of $\mathrm{CNO}$
$(500 \mathrm{nM})$ significantly increased firing rate in $\mathrm{PZ}$ Phox $2 \mathrm{~B}-\mathrm{hM} 3 \mathrm{Dq}$ neurons $(3.9 \pm 1.8$ vs. $1.4 \pm 1.2 \mathrm{~Hz}$ in control condition, $p=0.028$; Figure 7B2). CNO injection was successful in four of the five $\mathrm{PZ}^{\text {Phox2B-hM3Dq }}$ mice (one mouse displayed an atypical adverse reaction to the injection). CNO treatment during the light period (10:00) did not affect the hourly amounts of wakefulness (twoway ANOVA, $F(23,69)=1.26, p=0.23$; Figure 7C1), SWS (two-way ANOVA, $F(23,69)=1.21, p=0.27$; Figure 7C2) or REM sleep (two-way ANOVA, $F(23,69)=0.92, p=0.57$; Figure 7C3). In order to study the qualitative aspects of the sleep-wake cycle following activation of $\mathrm{PZ} \mathrm{Phox}^{\mathrm{PB}}$ neurons, we studied fragmentation (Figures 7D1-D3') and cortical EEG 


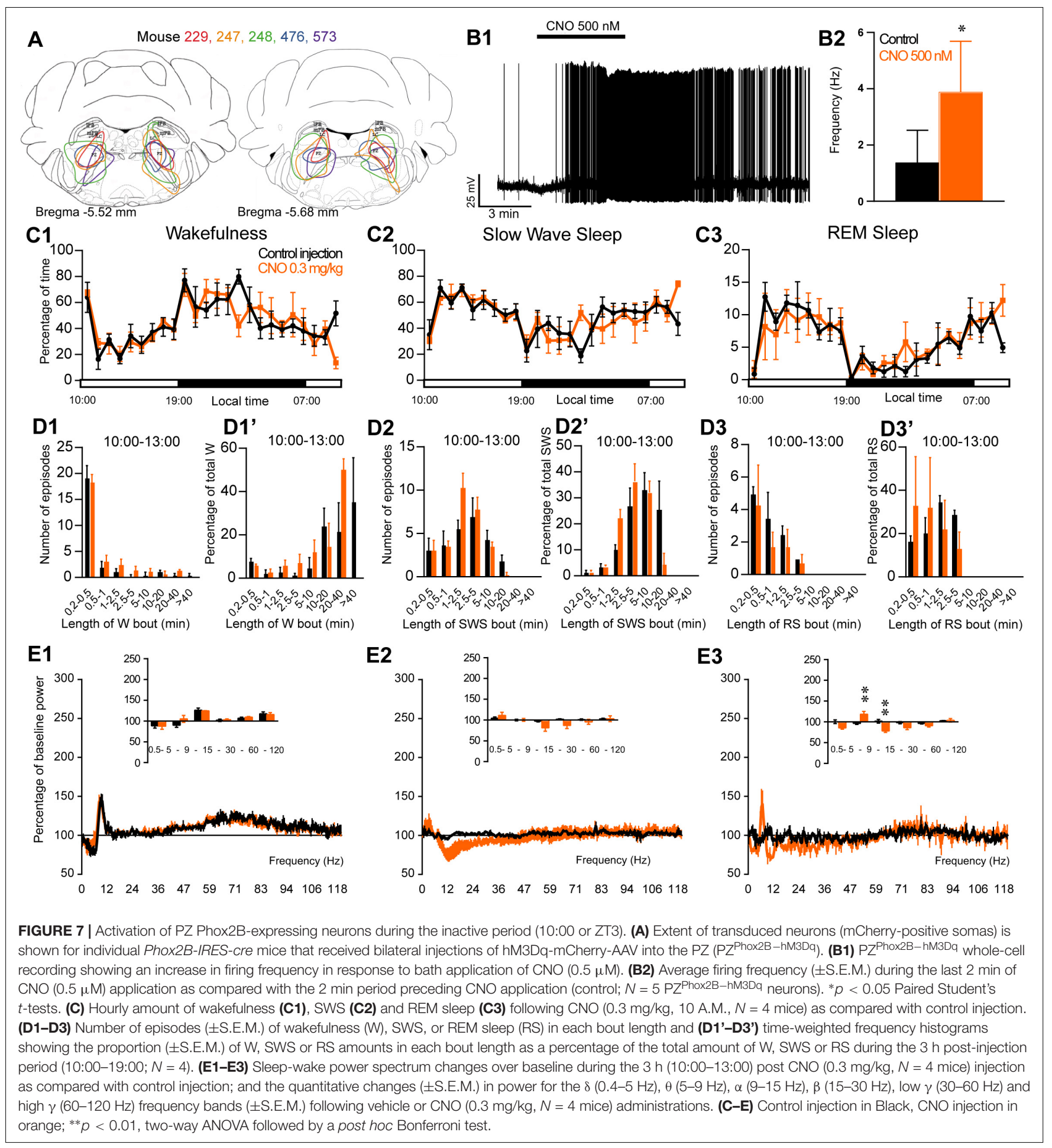

power distribution (Figures 7E1-E3) of the three vigilance stages during the $3 \mathrm{~h}$ post-injection time period. The number of sleep-wake episodes and episode length distribution were similar between CNO and control injections (Figures 7D1-D3). Treatment did not affect the cortical EEG power distribution during wakefulness and SWS. However, during REM sleep, the theta frequency band was significantly increased $(118.4 \pm 6.8$ vs.
$96.5 \pm 2.5 \%$ of baseline power in control condition, $p<0.01$; Figure 7D3) while the sigma frequency band was significantly decreased ( $78.4 \pm 3.8$ vs. $101.62 .5 \%$ of baseline power in control condition, $p<0.01$; Figure 7D3). These results indicate that activation of $\mathrm{PZ}$ Phox $2 \mathrm{~B}-\mathrm{hM} 3 \mathrm{Dq}$ during the light, inactive, period does not affect the sleep-wake cycle but could be involved in cortical EEG activation during REM sleep. Similar results were 


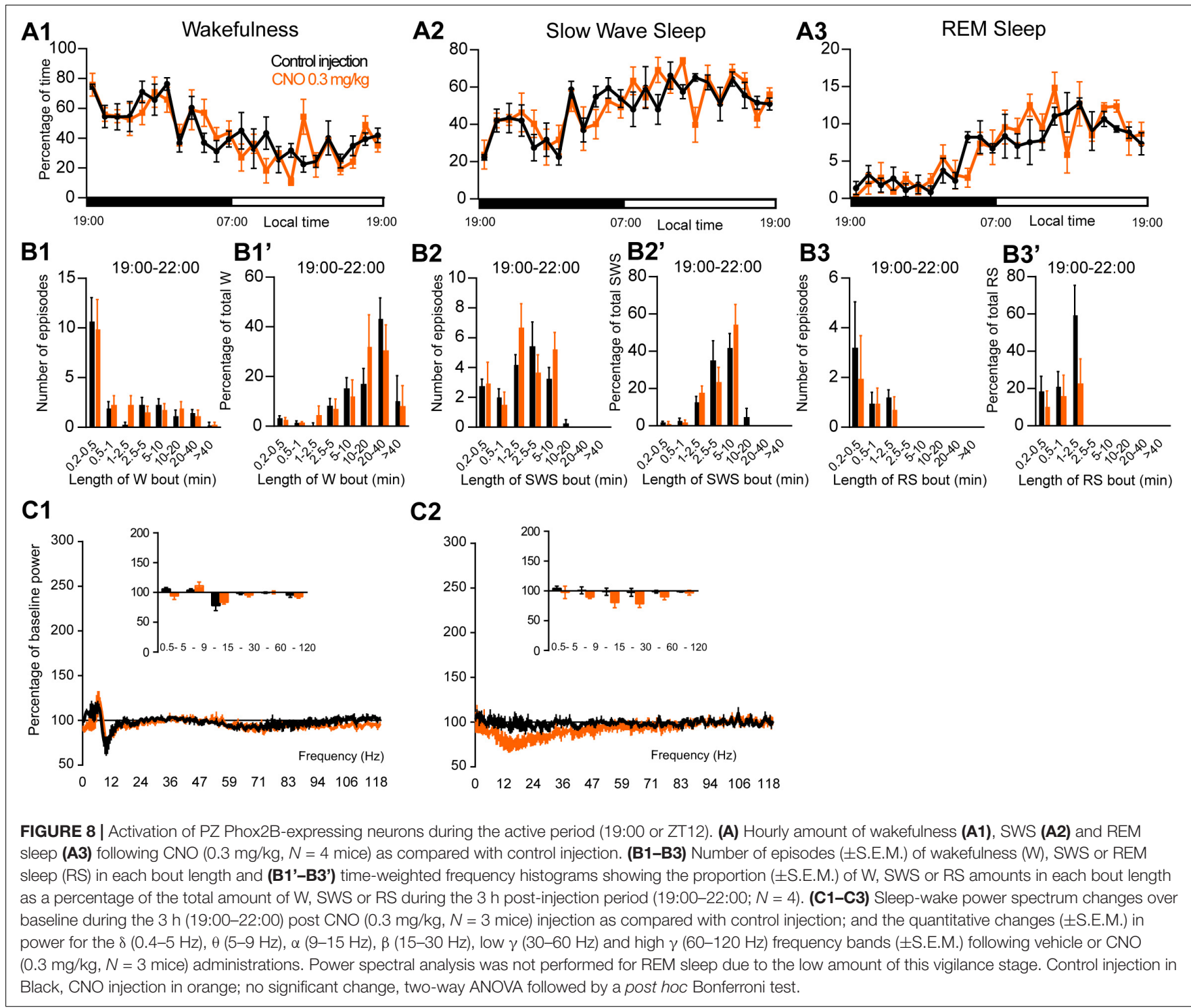

obtained when CNO was administrated at the beginning of the active period (19:00; Figure 8).

\section{DISCUSSION}

To test the contribution of $\mathrm{PZ}$ glutamatergic neurons in sleepwake control, we chemogenetically activated Vglut2-expressing neurons. Based on the sleep-wake phenotype and anatomical confirmation of the injection sites, the mice were separated in three groups: (1) one group, with targeted neuronal transfection mainly in the PZ, displayed increased wakefulness followed by a trend to increased REM sleep during the rest period but not during the active period; (2) a second group, with transfections that included the SLD, displayed a shorter wake increase followed by a significant increase in REM sleep amount; and (3) the third group, which had significant PB transfection, displayed a prominent and long lasting increase in wakefulness, independent of the time of day the injections were performed. Thus, due to the difficulty in targeting only glutamatergic PZ neurons while avoiding glutamatergic neurons in surrounding areas, the role of $\mathrm{PZ} \mathrm{Vglut}^{2}$ neurons in sleep-wake control was still unclear. CNO did not affect the sleep-wake cycle in control mice not expressing the hM3Dq receptor, confirming that the phenotypes seen in Vglut2 transfected mice were specifically due to the activation of glutamatergic neurons. To test the specific role of PZ glutamatergic neurons in sleep-wake control, we took advantage of Phox $2 \mathrm{~B}$, a transcription factor expressed by a subset of brainstem glutamatergic neurons. We first confirmed that Phox2B is a specific marker for PZ glutamatergic neurons in mice. Because chemogenetic activation of $\mathrm{PZ}{ }^{\mathrm{Phox} 2 \mathrm{~B}}$ neurons did not affect sleep-wake phenotypes, we can conclude that PZ glutamatergic neurons are not sufficient to influence the sleepwake cycle.

The absence of a sleep-wake phenotype in control and $\mathrm{PZ} \mathrm{Phox}^{\mathrm{PB}-\mathrm{hM} 3 \mathrm{Dq}}$ mice after $\mathrm{CNO}$ injection provides additional 
evidence that $\mathrm{CNO}$, at the dose used in our studies, does not affect the baseline sleep-wake cycle. A recent study had shown that clozapine, a metabolite of $\mathrm{CNO}$, but not $\mathrm{CNO}$, crosses the blood brain barrier and binds chemogenetic receptors with high affinity in rats (Gomez et al., 2017). This finding was subsequently challenged by the observation that both clozapine and $\mathrm{CNO}$ cross the blood brain barrier in mice, and that unbound $\mathrm{CNO}$ is present in the brain at concentrations sufficient to activate DREADDs, albeit at a higher initial dose than we typically use (Jendryka et al., 2019). We had previously shown that, at a dose of $0.3 \mathrm{mg} / \mathrm{kg}, \mathrm{CNO}$ does not affect sleep-wake quantity and quality in Vgat-IRES-cre mice (Anaclet et al., 2014), nor does it interfere with the wake-promoting actions of armodafinil and caffeine (Anaclet et al., 2018). In the present study, we confirm the absence of non-specific actions of CNO on the sleep-wake cycle, using two different mouse strains, Vglut2-IRES-cre and Phox2B-IRES-cre mice. Additionally, we confirmed that CNO is able to directly activate $\mathrm{PZ}$ Vglut2-hM3Dq, $\mathrm{PB}^{\mathrm{Vglut} 2-\mathrm{hM} 3 \mathrm{Dq}}$, and SLDVglut2-hM3Dq neurons in vitro, where the short application duration (few minutes) and the absence of hepatic metabolism make back-conversion to clozapine highly unlikely. In summary, $\mathrm{CNO}$ was able to activate glutamatergic neurons expressing hM3Dq chemogenetic receptor and did not result in non-specific sleep-wake phenotypes.

\section{Phox2B Is a Specific Marker for PZ Glutamatergic Neurons}

The transcription factor Phox2B has been studied for its involvement in the control of breathing and autonomic regulation. Phox2B mutations have been implicated in congenital central hypoventilation syndrome (Moreira et al., 2016). Phox2Bexpressing neurons located in the medullary retrotrapezoid nucleus (RTN), ventral from the facial nucleus, are sensitive to hypoxia (Onimaru et al., 2008), hypercapnic acidosis and serotonin ( $\mathrm{Wu}$ et al., 2019). Phox $2 \mathrm{~B}$ is necessary for the differentiation of central noradrenergic and adrenergic neurons (Pattyn et al., 2000; Huber et al., 2005). Phox2B is expressed in PZ in adult rats (Kang et al., 2007) but these neurons have no known physiological function. In the present study, we showed that, in PZ, Phox2B is highly co-localized with Vglut2 and therefore, is a specific marker for $\mathrm{PZ}$ glutamatergic neurons. Phox2B is also highly co-localized with LC noradrenergic neurons, known to be wake-promoting. However, in this study, the three mice showing partial expression of $\mathrm{hM} 3 \mathrm{Dq}$ receptors in $\mathrm{LC}$, did not display an increase in wake amount following CNO injection. It is possible that either the partial coverage of LC was not enough to promote wakefulness or LC noradrenergic neurons were not activated by the chemogenetic ligand. In vitro recordings of $\mathrm{LC}^{\text {Phox } 2 \mathrm{~B}-\mathrm{hM} 3 \mathrm{Dq}}$ neurons would be necessary to answer this question.

\section{The Role of PZ Glutamatergic Neurons in Sleep-Wake Control}

A previous study has suggested that some PZ non-GABAergic neurons are sleep-active (Anaclet et al., 2012). Because glutamatergic neurons are the only other neuronal population identified in PZ thus far, we tested if chemogenetic activation of PZ glutamatergic neurons affects sleep-wake phenotypes. Specific targeting of $\mathrm{PZ}$ glutamatergic neurons using Vglut2-cre mice was challenging. Of the over 29 injected mice, only six displayed hM3Dq expression mainly in PZ (PZ $\left.\mathrm{Pglut}^{\mathrm{V}-\mathrm{hM} 3 \mathrm{Dq}}\right)$. Five mice displayed hM3Dq expression mainly in $\mathrm{PB}\left(\mathrm{PB}^{\text {Vglut2 }-\mathrm{hM} 3 \mathrm{Dq}}\right)$ and six in SLD (SLD $\left.{ }^{\text {Vlut2-hM3Dq }}\right)$. The remaining mice included seven showing expression of hM3Dq at multiple sites, and five died after surgery or during the sleep recordings. These last two mouse groups were excluded from the study.

Chemogenetic activation of $\mathrm{PZ}$ Vglut2-hM3Dq neurons at the beginning of the mouse active phase (19:00) had limited impact on the sleep-wake cycle. On the other hand, chemogenetic activation of $\mathrm{PZ}$ glut2-hM3Dq neurons during the mouse rest phase (10:00) resulted in an early wake enhancement followed by an increase in REM sleep amount. Because these phenotypes are reminiscent of the phenotypes observed in $\mathrm{PB}^{\text {Vglut2-hM3Dq }}$ and SLD Vglut2-hM3Dq mice, we hypothesized that they were due to the inadvertent transfection of PB and SLD neurons. In other words, in the $\mathrm{PZ} \mathrm{Vglut}^{\mathrm{V}-\mathrm{hM} 3 \mathrm{Dq}}$ group, transfection would not be restricted to $\mathrm{PZ}$. To test this hypothesis and definitively confirm the role of $\mathrm{PZ}$ Vglut2 neurons in sleep-wake control, we took advantage of Phox $2 \mathrm{~B}$, a specific marker for $\mathrm{PZ}$ Vglut2 neurons. Using Phox2B-cre mice to specifically target $\mathrm{PZ}$ Vglut2 neurons and not neighboring $\mathrm{PB}$ and SLD, we showed that $\mathrm{PZ}$ Vglut2 neurons are not sufficient to affect the sleep-wake cycle at any time of the day. These results indicate that PZ glutamatergic neurons have no role in sleep or wake induction and/or maintenance. It remains, however, to be tested whether $\mathrm{PZ}^{\mathrm{Vglut} 2}$ neurons are necessary for normal sleep-wake cycle control, using inhibitory chemogenetic receptors and/or cell body specific lesion.

\section{A New Mouse Model for REM Sleep Enhancement}

Rostral to the PZ and PB, the SLD contains Vglut2-expressing neurons that are specifically active during REM sleep recovery (Clement et al., 2011). The SLD contains a large proportion of neurons with tonic discharge patterns immediately prior to and during REM sleep (Sakai, 2015). Cell body specific SLD lesions, knockout of glutamatergic transmission and genetic inactivation significantly reduce REM sleep amount and result in REM sleep without muscle atonia (Lu et al., 2006; Krenzer et al., 2011; Valencia Garcia et al., 2017). In the present study, we show for the first time that chemogenetic activation of SLD ${ }^{\text {glut2 }}$ neurons results in increased REM sleep amount and reduced SWS to REM sleep latency. Moreover, cortical EEG theta power is significantly enhanced during REM sleep. These data provide a new and unique model of REM sleep enhancement. Such a model will permit probing of the specific role of REM sleep in other neurophysiological functions, such as memory consolidation. However, specific targeting of SLD glutamatergic neurons is challenging due to the close proximity of $\mathrm{PB}$ wake-promoting glutamatergic neurons (Fuller et al., 2011). A specific marker for SLD glutamatergic neurons would be very useful. 


\section{Additional Evidence for the Importance of PB in Wakefulness}

In close proximity to $\mathrm{PZ}$, just dorsal, lateral and rostral, the $\mathrm{PB}$ is a critical brainstem wake-promoting system. Following lesions of both $\mathrm{PB}$ and precoeruleus (PC), rats can no longer sustain cortical activation and become comatose (Fuller et al., 2011). Since this seminal study, the role of PB glutamatergic neurons in wakefulness has been refined. Specific lesions of medial PB result in hypersomnolence (Kaur et al., 2013). Glutamatergic neurons located in the external lateral PB are activated by hypoxia and are a key component of the vitally important circuitry regulating arousal from sleep apnea episodes (Kaur et al., 2017). In the present study we show that chemogenetic activation of medial PB results in long lasting wake enhancement. Moreover, $\mathrm{CNO}$ induced wakefulness was characterized by a decreased delta frequency band power. Because the delta band is considered a marker of EEG synchronization and is more prominent during quiet wakefulness, this result indicates a more active wake state induced by activation of $\mathrm{PB}^{\text {Vglut2 }}$ neurons. Finally, no sleep rebound was seen after the wake enhancement. This is in accordance with previous studies using chemogenetics to specifically activate wake-promoting neuronal populations (Anaclet et al., 2015; Venner et al., 2016; Pedersen et al., 2017) and indicates that chemogenetic activation of wake-promoting neuronal populations does not enhance the homeostatic drive for sleep. All together, these results confirm the strong wake-promoting action of $\mathrm{PB}$ glutamatergic neurons.

\section{CONCLUSION}

This study shows, for the first time, that PZ glutamatergic neurons are not sufficient to affect the sleep-wake cycle in mouse. However, chemogenetic activation of $\mathrm{PB}$ or SLD glutamatergic neurons results in wake or REM sleep enhancement, respectively. Finally, Phox2B is a specific marker for PZ glutamatergic neurons. All together, these results provide a better understanding on how the brain regulates sleep-wake

\section{REFERENCES}

Alam, M. A., Kostin, A., Siegel, J., McGinty, D., Szymusiak, R., and Alam, M. N. (2018). "Characteristics of sleep-active neurons in the medullary parafacial zone in rats". Sleep 41:zsy130. doi: 10.1093/sleep/zsy130

Anaclet, C., Griffith, K., and Fuller, P. M. (2018). Activation of the GABAergic parafacial zone maintains sleep and counteracts the wake-promoting action of the psychostimulants armodafinil and caffeine. Neuropsychopharmacology 43, 415-425. doi: 10.1038/npp.2017.152

Anaclet, C., Ferrari, L., Arrigoni, E., Bass, C. E., Saper, C. B., Lu, J., et al. (2014). The GABAergic parafacial zone is a medullary slow wave sleep-promoting center. Nat. Neurosci. 17, 1217-1224. doi: 10.1038/nn.3789

Anaclet, C., and Fuller, P. M. (2017). Brainstem regulation of slow-wave-sleep. Curr. Opin. Neurobiol. 44, 139-143. doi: 10.1016/j.conb.2017.04.004

Anaclet, C., Lin, J. S., Vetrivelan, R., Krenzer, M., Vong, L., Fuller, P. M., et al. (2012). Identification and characterization of a sleep-active cell group in cycles, forming a framework for future studies characterizing the sleep-promoting subpopulation of the PZ.

\section{DATA AVAILABILITY}

The raw data supporting the conclusions of this manuscript will be made available by the authors, without undue reservation, to any qualified researcher.

\section{ETHICS STATEMENT}

All procedures were approved by the Institutional Animal Care and Use Committee of Beth Israel Deaconess Medical Center and of University of Massachusetts Medical School.

\section{AUTHOR CONTRIBUTIONS}

EE performed the immunostaining and analyzed the sleep data. LF performed and analyzed the in vitro experiments. HG performed and analyzed the in situ hybridization experiments and wrote the manuscript. CA performed the surgeries and the in vivo experiments, and wrote the manuscript.

\section{FUNDING}

This research was funded by the National Institutes of Health grants K99MH103399 (CA) and R00MH103399 (CA), Coins for Alzheimer's Research Trust (CART) fund and by the University of Massachusetts Medical School startup funds. The latter were used to fund the open access publication fees.

\section{ACKNOWLEDGMENTS}

We are grateful to Quan Hue Ha, Minh Ha, Myriam Debryune, Rebecca Broadhurst, and Tilar Martin for superb technical assistance. We thank Dr. Patrick Fuller for his support.

the rostral medullary brainstem. J. Neurosci. 32, 17970-17976. doi: 10.1523/ JNEUROSCI.0620-12.2012

Anaclet, C., Pedersen, N. P., Ferrari, L. L., Venner, A., Bass, C. E., Arrigoni, E., et al. (2015). Basal forebrain control of wakefulness and cortical rhythms. Nat. Commun. 6:8744. doi: 10.1038/ncomms 9744

Anaclet, C., Pedersen, N. P., Fuller, P. M., and Lu, J. (2010). Brainstem circuitry regulating phasic activation of trigeminal motoneurons during REM sleep. PLoS One 5:e8788. doi: 10.1371/journal.pone.0008788

Clement, O., Sapin, E., Berod, A., Fort, P., and Luppi, P. H. (2011). Evidence that neurons of the sublaterodorsal tegmental nucleus triggering paradoxical (REM) sleep are glutamatergic. Sleep 34, 419-423. doi: 10.1093/sleep/34. 4.419

Fuller, P. M., Sherman, D., Pedersen, N. P., Saper, C. B., and Lu, J. (2011). Reassessment of the structural basis of the ascending arousal system. J. Comp. Neurol. 519, 933-956. doi: 10.1002/cne.22559 
Gomez, J. L., Bonaventura, J., Lesniak, W., Mathews, W. B., Rodriguez, L. A., and Ellis, R. J. (2017). Chemogenetics revealed: dREADD occupancy and activation via converted clozapine. Science 357, 503-507. doi: 10.1126/science.aan 2475

Huber, K., Karch, N., Ernsberger, U., Goridis, C., and Unsicker, K. (2005). The role of Phox2B in chromaffin cell development. Dev. Biol. 279, 501-508. doi: 10.1016/j.ydbio.2005.01.007

Jendryka, M., Palchaudhuri, M., Ursu, D., Liss, B., Katzel, D., Nissen, W., et al. (2019). Pharmacokinetic and pharmacodynamic actions of clozapine-N-oxide, clozapine, and compound 21 in DREADD-based chemogenetics in mice. Sci. Rep. 9:4522. doi: 10.1038/s41598-019-41088-2

Kang, B. J., Chang, D. A., Mackay, D. D., West, G. H., Moreira, T. S., Takakura, A. C., et al. (2007). Central nervous system distribution of the transcription factor Phox2b in the adult rat. J. Comp. Neurol. 503, 627-641. doi: 10.1002/cne. 21409

Kantor, S., Mochizuki, T., Lops, S. N., Ko, B., Clain, E., Clark, E., et al. (2013). Orexin gene therapy restores the timing and maintenance of wakefulness in narcoleptic mice. Sleep 36, 1129-1138. doi: 10.5665/sleep. 2870

Kaur, S., Pedersen, N. P., Yokota, S., Hur, E. E., Fuller, P. M., Lazarus, M., et al. (2013). Glutamatergic signaling from the parabrachial nucleus plays a critical role in hypercapnic arousal. .J. Neurosci. 33, 7627-7640. doi: 10.1523/ JNEUROSCI.0173-13.2013

Kaur, S., Wang, J. L., Ferrari, L., Thankachan, S., Kroeger, D., Venner, A., et al. (2017). A Genetically defined circuit for arousal from sleep during hypercapnia. Neuron 96, 1153.e5-1167e5. doi: 10.1016/j.neuron.2017.10.009

Krenzer, M., Anaclet, C., Vetrivelan, R., Wang, N., Vong, L., Lowell, B. B., et al. (2011). Brainstem and spinal cord circuitry regulating REM sleep and muscle atonia. PLoS One 6:e24998. doi: 10.1371/journal.pone.0024998

Liu, J., Krautzberger, A. M., Sui, S. H., Hofmann, O. M., Chen, Y., Baetscher, M., et al. (2014). Cell-specific translational profiling in acute kidney injury. J. Clin. Invest. 124, 1242-1254. doi: 10.1172/JCI72126

Lu, J., Sherman, D., Devor, M., and Saper, C. B. (2006). A putative flip-flop switch for control of REM sleep. Nature 441, 589-594. doi: 10.1038/nature04767

Mochizuki, T., Crocker, A., McCormack, S., Yanagisawa, M., Sakurai, T., and Scammell, T. E. (2004). Behavioral state instability in orexin knock-out mice. J. Neurosci. 24, 6291-6300. doi: 10.1523/jneurosci.0586-04.2004

Moreira, T. S., Takakura, A. C., Czeisler, C., and Otero, J. J. (2016). Respiratory and autonomic dysfunction in congenital central hypoventilation syndrome. J. Neurophysiol. 116, 742-752. doi: 10.1152/jn.00026.2016

Onimaru, H., Ikeda, K., and Kawakami, K. (2008). $\mathrm{CO}_{2}$-sensitive preinspiratory neurons of the parafacial respiratory group express Phox $2 \mathrm{~b}$ in the neonatal rat. J. Neurosci. 28, 12845-12850. doi: 10.1523/JNEUROSCI.3625-08.2008

Pattyn, A., Goridis, C., and Brunet, J. F. (2000). Specification of the central noradrenergic phenotype by the homeobox gene Phox2b. Mol. Cell. Neurosci. 15, 235-243. doi: 10.1006/mcne.1999.0826
Paxinos, G. T., and Franklin, K. B. J. (2001). The Mouse Brain in Stereotaxic Coordinates, 2 Edn. San Diego: Academic.

Pedersen, N. P., Ferrari, L., Venner, A., Wang, J. L., Abbott, S. B. G., Vujovic, N., et al. (2017). Supramammillary glutamate neurons are a key node of the arousal system. Nat. Commun. 8:1405. doi: 10.1038/s41467-017-01004-6

Rossi, J., Balthasar, N., Olson, D., Scott, M., Berglund, E., Lee, C. E., et al. (2011). Melanocortin-4 receptors expressed by cholinergic neurons regulate energy balance and glucose homeostasis. Cell Metab. 13, 195-204. doi: 10.1016/j.cmet. 2011.01.010

Sakai, K. (2015). Paradoxical (rapid eye movement) sleep-on neurons in the laterodorsal pontine tegmentum in mice. Neuroscience 310, 455-471. doi: 10. 1016/j.neuroscience.2015.09.063

Sakai, K. (2017). Are there sleep-promoting neurons in the mouse parafacial zone? Neuroscience 367, 98-109. doi: 10.1016/j.neuroscience.2017.10.026

Stornetta, R. L., Moreira, T. S., Takakura, A. C., Kang, B. J., Chang, D. A., West, G. H., et al. (2006). Expression of Phox $2 b$ by brainstem neurons involved in chemosensory integration in the adult rat. J. Neurosci. 26, 10305-10314. doi: 10.1523/JNEUROSCI.2917-06.2006

Valencia Garcia, S., Libourel, P. A., Lazarus, M., Grassi, D., Luppi, P. H., and Fort, P. (2017). Genetic inactivation of glutamate neurons in the rat sublaterodorsal tegmental nucleus recapitulates REM sleep behaviour disorder. Brain 140, 414-428. doi: 10.1093/brain/aww310

Venner, A., Anaclet, C., Broadhurst, R. Y., Saper, C. B., and Fuller, P. M. (2016). A Novel Population of wake-promoting GABAergic neurons in the ventral lateral hypothalamus. Curr. Biol. 26, 2137-2143. doi: 10.1016/j.cub.2016. 05.078

Vong, L., Ye, C., Yang, Z., Choi, B., Chua, S Jr, and Lowell, B. B. (2011). Leptin action on GABAergic neurons prevents obesity and reduces inhibitory tone to POMC neurons. Neuron 71, 142-154. doi: 10.1016/j.neuron.2011.05.028

Wu, Y., Proch, K. L., Teran, F. A., Lechtenberg, R. J., Kothari, H., and Richerson, G. B. (2019). Chemosensitivity of Phox 2 b-expressing retrotrapezoid neurons is mediated in part by input from 5-HT neurons. J. Physiol. 597, 2741-2766. doi: 10.1113/JP277052

Conflict of Interest Statement: The authors declare that the research was conducted in the absence of any commercial or financial relationships that could be construed as a potential conflict of interest.

Copyright (c) 2019 Erickson, Ferrari, Gompf and Anaclet. This is an open-access article distributed under the terms of the Creative Commons Attribution License (CC BY). The use, distribution or reproduction in other forums is permitted, provided the original author(s) and the copyright owner(s) are credited and that the original publication in this journal is cited, in accordance with accepted academic practice. No use, distribution or reproduction is permitted which does not comply with these terms. 